\title{
Interaction between innate immunity and porcine reproductive and respiratory syndrome virus
}

\author{
Yongming Sang ${ }^{1}$, Raymond R. R. Rowland ${ }^{2}$ and Frank Blecha ${ }^{1}$ * \\ ${ }^{1}$ Departments of Anatomy and Physiology, College of Veterinary Medicine, Kansas State University, \\ Manhattan, KS, USA, \\ ${ }^{2}$ Diagnostic Medicine and Pathobiology, College of Veterinary Medicine, Kansas State University, \\ Manhattan, KS, USA
}

Received 19 September 2011; Accepted 18 October 2011; First published online 29 November 2011

\begin{abstract}
Innate immunity provides frontline antiviral protection and bridges adaptive immunity against virus infections. However, viruses can evade innate immune surveillance potentially causing chronic infections that may lead to pandemic diseases. Porcine reproductive and respiratory syndrome virus (PRRSV) is an example of an animal virus that has developed diverse mechanisms to evade porcine antiviral immune responses. Two decades after its discovery, PRRSV is still one of the most globally devastating viruses threatening the swine industry. In this review, we discuss the molecular and cellular composition of the mammalian innate antiviral immune system with emphasis on the porcine system. In particular, we focus on the interaction between PRRSV and porcine innate immunity at cellular and molecular levels. Strategies for targeting innate immune components and other host metabolic factors to induce ideal antiPRRSV protection are also discussed.
\end{abstract}

Keywords: innate antiviral immunity, PRRSV, interferon, vaccine

\section{Introduction}

The immune system in higher vertebrates involves both innate and adaptive immune responses (Pancer and Cooper, 2006). Innate immune mechanisms, which exist in all organisms from bacteria to humans, provide immediate frontline protection against infections (Beutler, 2004; Pancer and Cooper, 2006). Evidence from both the host and virus indicates that invoking early and appropriate innate immune responses is critical for the outcome of most viral diseases, determining whether an infection is controlled or whether a persistent infection develops (Beutler, 2004; Pancer and Cooper, 2006). The critical role of innate immune cells and their components not only dominates antiviral activity in the early phase of infection, but also potentiates the adaptive immune system for viral clearance (Hoebe et al., 2004; Kabelitz and Medzhitov,

*Corresponding author. E-mail: blecha@vet.k-state.edu
2007). In this review, we provide a brief discussion of the major components of the innate antiviral immune system with particular emphasis on porcine-specific features. Our emphasis is on the response to and subversion of porcine innate antiviral immunity during infection caused by porcine reproductive and respiratory syndrome virus (PRRSV). For more general discussions about the challenges of PRRSV immunology and vaccinology, the reader is referred to several recent reviews (Kimman et al., 2009; Darwich et al., 2010; Yoo et al., 2010).

\section{Overview of mammalian innate antiviral immune system}

\section{Innate immune cells}

A highly differentiated immune system appears to offer an evolutionary advantage to higher vertebrates. Nonetheless, all nucleated cells are readily capable of mounting 


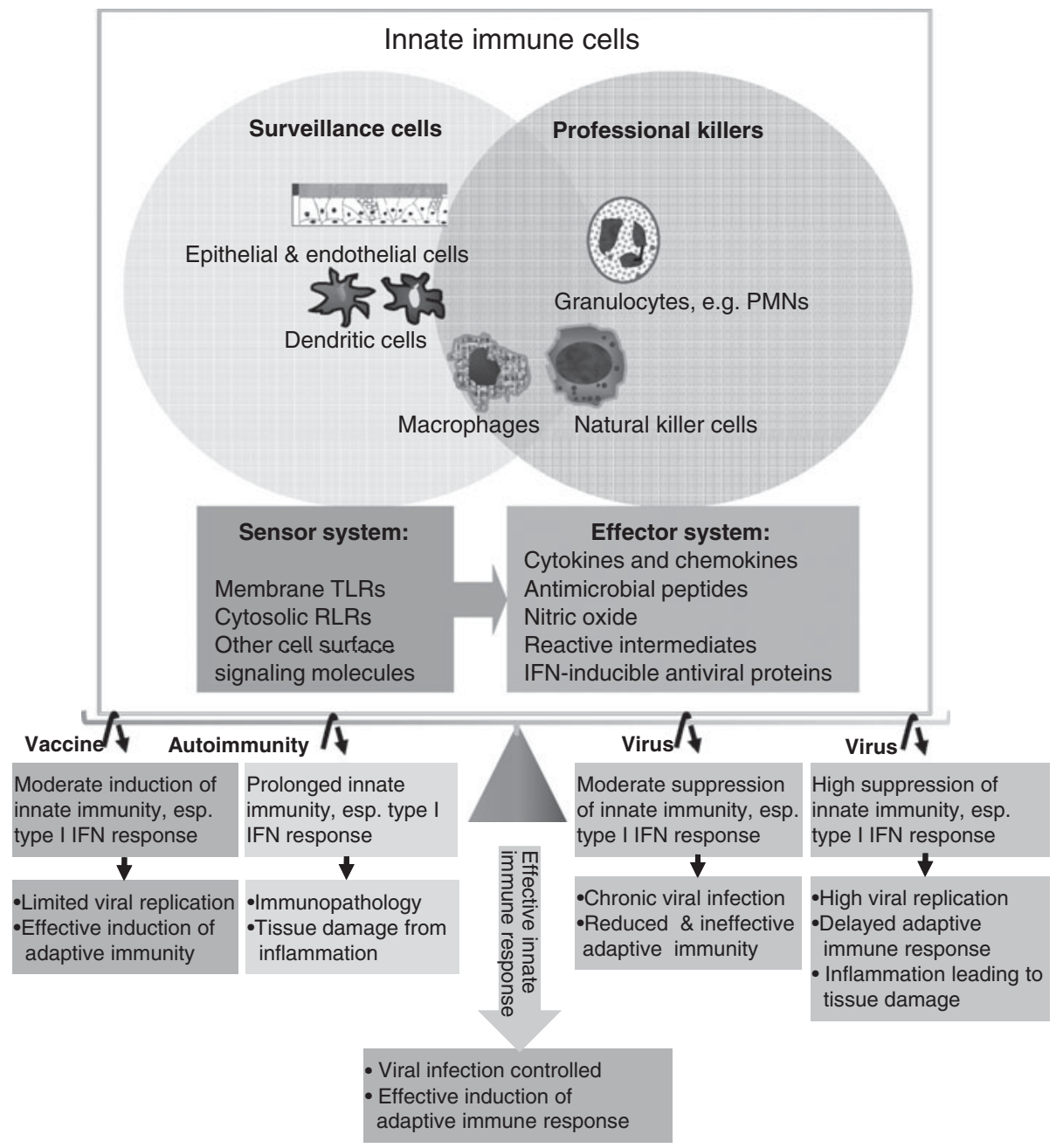

Fig. 1. Innate immune homeostasis and interaction with viral infection. Innate immune cells exert antiviral activities of immune surveillance and direct inactivation using various virus-sensing and effector molecules. Whereas most viral attacks are controlled through innate immunity and synergistic induction of adaptive immunity (including vaccine-induced), virus isolates or species that have the capability to divert innate immunity, especially type I IFN responses, alter innate immune balance causing pandemic diseases (Katze et al., 2008).

innate immune responses upon exposure to a virus (Beutler, 2004). Mammalian innate immune cells, which are specialized for various functions such as pathogen recognition and killing, immune surveillance and antigen presentation, include granulocytes, natural killer (NK) cells, macrophages and dendritic cells (DCs), as well as epithelial and endothelial cells. Granulocytes, macrophages and NK cells are well documented for their role as effector cells in engulfing and digesting microorganisms or promoting active death of infected cells (Ludwig et al., 2006; Appelberg, 2007; Takeuchi and Akira, 2007; Vivier et al., 2008). Depending on their anatomical locations, epithelial and endothelial cells, as well as DCs and macrophages, are among the first groups of cells initially exposed to viruses (Barchet et al., 2005; Opitz et al., 2007; Wen et al., 2008; Hammad and Lambrecht, 2008). Their function in viral recognition and immune surveillance facilitates coordination of subsequent immune responses by linking to adaptive immunity.
Innate immune cells are dually functional as 'sensors' and 'effectors'. Even cells that are primarily associated with killing, e.g., neutrophils, facilitate immune surveillance via Toll-like receptors (TLRs) (Haselmayer et al., 2006; Borregaard et al., 2007). Furthermore, professional antigen presenting cells, such as conventional DCs, potently destroy engulfed pathogens through autophagy (Schmid et al., 2006; Lee and Iwasaki, 2008). This functional plasticity is best known in macrophages, which are composed of diverse subgroups of professional phagocytes as well as immunoregulatory cells (Figure 1; Hashimoto et al., 2007; Kumagai et al., 2007; Randolph et al., 2008). Because innate immune cells such as macrophages, epithelial cells and endothelial cells, often serve as the initial foothold for viral infection, these cells provide an excellent platform for examining virus-host interaction, viral recognition, signaling transduction and antiviral effector function (Opitz et al., 2007; Hammad and Lambrecht, 2008; Wen et al., 2008). 
Accumulated evidence indicates that upon viral infection the overall immune response is dependent on the coordination of innate immune cells to exert immune surveillance and to produce immune effectors. The balance resulting from immune regulation or vaccineinduced innate-immune activation will elicit both innate and adaptive immunity to control virus replication. In contrast, if viruses divert the induction of innate immunity, especially a type I interferon (IFN) response, it is likely that disease will result from uncontrolled viral infections (Figure 1; Katze et al., 2008). DCs and activated macrophages are antigen-presenting cells, which directly bridge innate and adaptive immunity. In addition, some newly defined groups of innate immune cells including innate lymphoid cells (ILCs), natural helper cells (NHCs) and innate type 2 helper cells (ih2), which are crucial for the development of lymphoid structures and secrete cytokines similar to those from $\mathrm{T}$ helper cells, are also important players that bridge innate and adaptive immunity. However, their role in antiviral responses remains obscure (Sawa et al., 2010; Saenz et al., 2010; Veldhoen and Withers, 2010).

Monocytes represent $10-30 \%$ of all peripheral blood mononuclear cells (PBMC) and are progenitors of most tissue macrophages (Randolph et al., 2008; Cassol et al., 2010). These myeloid monocytes circulate for about 1-2 days before migrating into peripheral tissues and differentiating into resident tissue macrophages (Martinez et al., 2009). Macrophages are anatomically and functionally heterogeneous. Tissue-specific macrophages are specific to anatomic locations including blood monocytes, peritoneal macrophages, pulmonary macrophages, Kupffer cells in the liver and microglia in the brain (Taylor et al., 2005; Naito, 2008; Randolph et al., 2008). Even within an organ, macrophages are further categorized based on their micro-anatomical location. The lung provides an example of this macrophage categorization. For example, pulmonary macrophages can be divided into three subgroups based on their microenvironment within the lung: pulmonary alveolar macrophages (PAMs), pulmonary intravascular macrophages (PIMs) and interstitial macrophages (ISMs) (Naito, 2008; Randolph et al., 2008).

PAMs are the most abundant pulmonary immune cells in the alveolus located at the interface between air and lung tissues. Substantial numbers of ISMs are detected within the lung stroma and PIMs are mature phagocytes adhered to capillary endothelial cells within the lung that cover approximately $16 \%$ of the lung capillary surface in species such as pigs and ruminants (Chitko-McKown and Blecha, 1992). With respect to airway viral infections, PAMs are first to express early activation for scavenging and killing mucus-trapped viral particles through phagocytosis. To fulfill this task, activated PAMs are equipped with a variety of surface and internal receptors to detect antibody/complement-engaged viral particles (by surface Fc or complement receptors) and to recognize viral components by membrane-associated or cytosolic receptors (Fantuzzi et al., 2003; Beisswenger and Bals, 2005; Daffis et al., 2007; Kumagai et al., 2007). PAMs are very active killer cells known to inactivate trapped viruses with both oxidative and non-oxidative mechanisms and to lower the chance of airborne viruses initializing infections on pneumocytes as well as pulmonary endothelial cells (Taylor et al., 2005; Naito, 2008; Randolph et al., 2008). PAMs are activated through phagocytosis or receptor recognition of viral components. They are active producers of type I IFNs and other pro-inflammatory cytokines, which lead to antiviral responses including the regulatory loop by type I IFNs and recruitment of other immune cells to infection sites (Kumagai et al., 2007; Takeuchi and Akira, 2007). Normally, PAMs represent $>90 \%$ of immune cells in bronchoalveolar lavage (BAL) fluid prior to the increase of granulocytes in BAL fluid after an infection (White et al., 2007). PAMs have been identified as the primary IFN- $\alpha$ producer in murine models upon respiratory viral infections (Kumagai et al., 2007; Takeuchi and Akira, 2007).

Compared to PAMs, ISMs are less phagocytic and potentially more active in repairing tissue damage. PIMs are highly phagocytic and mainly exist in ruminants, pigs and horses (Longworth, 1997). Compared to PAMs, porcine PIMs are almost equally permissive to PRRSV infection and their bactericidal and phagocytic activities are significantly suppressed by PRRSV infection much like PAMs (Thanawongnuwech et al., 2000).

The importance of macrophages in an antiviral immune response is also reflected by the virus' ability to surpass this first line of surveillance allowing for a much higher chance of escaping innate immune defenses in turn causing persistent infections. Several viruses possess the ability to directly infect and undermine immune responses (such as production and signaling of type I IFNs) of macrophages (Table 1). For example, macrophages infected by human immunodeficiency virus-1 (HIV-1) and PRRSV are functionally compromised in many ways including cytokine production, receptor expression, phagocytosis and antigen presentation (Ieong et al., 2000; Martinelli et al., 2007; Darwich et al., 2010; Thanawongnuwech and Suradhat, 2010). In this regard, direct infection of macrophages may divert overall homeostasis of cell activation status causing exacerbating co-infections and complicated syndromes.

Macrophages have been classified into two major types according to their activation status and functional difference: the classical type 1 macrophages (M1) and alternative type 2 macrophages (M2). M1 cells are conventionally activated by Th1 cytokines such as IFN- $\gamma$ and IL-12. Alternatively, M2 macrophages are more heterogeneous than M1 cells depending on the stimuli. M2a macrophages are induced by Th2 cytokines such as IL-4/IL-13, while M2b macrophages are activated by immune complexes, TLR stimulation, or by IL-1Ra. M2C macrophages are generated by stimulation with the 
Table 1. Innate immune evasion mechanisms of various monocytotropic viruses

Virus: [genome, family]

HRSV: [(-)ssRNA,

Paramyxoviridae]

IVA: [Segmented (-)RNA,

Orthomyxoviridae]

SARS-CoV: $[(+)$ ssRNA,

Coronaviridae]

HIV1: [(+)ssRNA, Retroviridae]

PRRs*

Multiple TLRs,

RIG-I, PKR

Multiple TLRs and RLRs

Mechanism and effect on type I IFN and other cytokine production*

Viral NS1 and NS2 proteins inhibit IFN production and signaling;

stimulates the production of Th2 cytokines and IL-10 to skew alternative activation of macrophages

NS1 gene product inhibits IFN secretion and activity; suppresses IL-8 production; pandemic strains may skew $\mathrm{M} 2 \mathrm{~b}$ and Th2 response through immune complexes

MyD88-dependent TLRs A papain-like protease inhibits IFN secretion via IRF3 interference; elevates pro-inflammatory cytokines and chemokines in lung and blood

Multiple TLRs

SeV: $[(-)$ ssRNA, Paramyxoviridae]

CSFV: [(+)ssRNA, Flaviviridae]

Multiple TLRs and RLRs

Skews M1 activation at acute phase for establishing viral reservoirs and M2 macrophages transmission and leads to immune failure at late stages

Multiple TLRs

PrV: [dsDNA, Herpesviridae]

Viral DNA sensors?

Viral protein $\mathrm{N}$ mediates IRF3 degradation and suppresses IFN production, but no modulation of IL-10 and pro-inflammatory cytokines Viral EP0 protein targets STAT1 to prevent IFN-induced antiviral state may suppress IL-12 production

TLR3

Strain-dependent suppression of TLR3 signaling and IFN response; highly virulent strains are more potent suppressors of IFN and pro-inflammatory cytokine production

Possible TLR7/9

Impairs TLR9 ligand-induced IFN and pro-inflammatory cytokine production; stimulates IL-10 production of bystander T cells but not infected macrophages

Viral L protein mediates suppression of IFN synthesis and ISG induction; induces IL-10 production of pDCs during acute phase for immune suppression

Viral NSPs target IRF3, IRF7 and ISG3 to suppress IFN production and signaling; induction of IL-10 and suppression of IL-12 has been observed
References

Schlender et al. (2005)

Munir et al. (2008),

Shirey et al. (2010)

Ehrhardt (2010),

Koyama et al. (2007),

Calzada-Nova et al. (2010a, b),

Monsalvo et al. (2011)

Chen and Subbarao (2007),

Devaraj et al. (2007),

Sheahan et al. (2008)

Thibault et al. (2009)

Sanders et al. (2008),

Herbein and Varin (2010)

Kato et al. (2007),

Bousse et al. (2006)

Carrasco et al. (2004),

Bauhofer et al. (2007)

Brukman and Enquist (2006a, b),

Calzada-Nova et al. (2010a, b)

Afonso et al. (2004),

Zhang et al. (2006),

Gil et al. (2008),

de Oliveira et al. (2011)

Chang et al. (2006),

Vincent et al. (2007),

Wikström et al. (2011)

de Los Santos et al. (2006, 2007

2009), Diaz-San Segundo et al.

(2009, 2010)

Fang and Snijder (2010),

Yoo et al. (2010),

Calzada-Nova et al. (2010a, b)

*Based on information from PAMs and other cells. ASFV, African swine fever virus; CSFV, classical swine fever virus; HIV1, human immune-deficiency virus-1; HRSV, human respiratory syncytial virus; IVA: human (swine) Influenza A; SAR, severe acute respiratory syndrome coronavirus; SeV, mouse Sendai virus; PCV2, porcine circovirus-2; PFMDV,

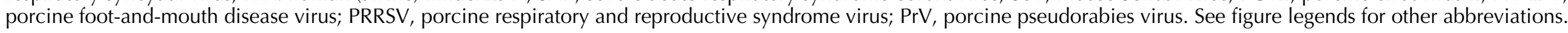


immune suppressive cytokine IL-10 and glucocorticoids (Martinez et al., 2009; Herbein and Varin, 2010; Odegaard and Chawla, 2011). In general, M1 macrophages are pro-inflammatory and induce cellular immunity with higher microbicidal as well as tissue-destructive activities. $\mathrm{M} 2 \mathrm{a} / \mathrm{b}$ cells are anti-inflammatory and induce humoral immunity with higher anti-parasite, tissue repairing as well as allergic activities. In contrast, deactivated M2c macrophages are primarily immunosuppressive along with secretion of anti-inflammatory cytokines (Martinez et al., 2009; Herbein and Varin, 2010; Odegaard and Chawla, 2011). Accumulated evidence indicates that macrophages are functionally plastic cells with the potential to alter their activities progressively and reversibly in response to changes in the tissue environment (Stout et al., 2009). For example, mouse peripheral monocytes or peritoneal macrophages shift from M2a to M2c or from M1 to M2 after sequential treatment with corresponding cytokines (Stout et al., 2005). Thus, hypothetically, macrophages at different activation statuses vary in their antimicrobial activity or capacity to resolve tissue damage from infections.

The link between macrophage polarization and virus infection has recently been studied in HIV-1 and respiratory syncytial virus (RSV)-infected human and murine cells (Cassol et al., 2009; Shirey et al., 2010). In vitro polarization of human blood monocytes into M1 cells prevents HIV-1 infection and M2a polarization inhibits viral replication at a post-integration level but facilitates macrophage-mediated transmission of HIV-1 to $\mathrm{CD}^{+}{ }^{+} \mathrm{T}$ cells (Cassol et al., 2009). In mice, RSV infection induces acute inflammatory responses at the early phase, but macrophages are skewed to the M2 phenotype progressively during the later phase of infection (Shirey et al., 2010). This alternative transition of macrophages counteracts the early inflammatory responses for resolution of tissue damage, but decreases the higher antiviral ability associated with the M1 state, which may help prevent virus escape from innate immune surveillance. In addition, if the M2 phenotype persists, it may lead to a 'Th2-skewed' adaptive immune response resulting in hypersensitivity to allergies and autoimmune diseases (Shirey et al., 2010). The increase of deactivated M2c macrophages in response to IL-10 and glucocorticoids at a later phase of viral infection decreases aggressive immune responses thus limiting pathological damage. However, some viruses, such as RSV and possibly PRRSV, may escape this mechanism facilitating the development of persistent/chronic infection. Therefore, the macrophage polarization scheme provides a valuable and straightforward framework for investigating the complexity of hostvirus interaction in macrophages (Herbein and Varin, 2010).

There is broad divergence regarding permissiveness of porcine macrophages to PRRSV infection and although the activation status of macrophage subsets is critical in supporting virus infection and replication, this scheme has yet to be studied in pigs. In this respect, the differential expression of virus receptors [including heparin, sialoadhesin (CD169) and the scavenger receptor CD163] and immunomodulating cytokines should be scrutinized in different subsets of macrophages due to determinants correlating with macrophage activation and PRRSV permissiveness. Interestingly, in addition to membrane-bound CD163, a large amount of soluble CD163 is present in the circulation. It will be informative to determine how circulating soluble CD163 interacts with PRRSV (Van Gorp et al., 2008; Patton et al., 2009; Welch and Calvert, 2010). In addition, an increase of IL-10 and glucocorticoids as well as suppression of IFNs has been associated with PRRSV infection. It remains to be determined whether these changes contribute to deactivation of macrophages and thereby to PRRSV pathogenesis (Borghetti et al., 2011).

Macrophages are abundant in mucosal membranes and, unlike DCs, do not migrate to distal tissues. PRRSV exists in tonsils and lymphoid nodes of infected piglets and a recent study of vertical transmission has shown that the targets of PRRSV replication are in the fetal thymus and presumably are monocytic (Rowland, 2010). Therefore, macrophages are likely contributors to PRRSV pathogenesis leading to infected DCs and blood monocytes, which may be more responsible for viral transmission in lymphatic tissues.

DCs represent a primary group of innate immune cells that bridge innate and adaptive immune responses (Iwasaki, 2007; Hammad and Lambrecht, 2008; Wen et al., 2008). The two major types of DCs are classified as conventional and plasmacytoid DCs (cDCs and pDCs, respectively). The $\mathrm{CDCs}$ are prominent antigen-presenting cells with high autophagy activity (a process to uptake an antigen). Although cDCs are very important in antigen presentation for $\mathrm{T}$ cells in secondary lymphoid tissues, no direct antiviral role of peripheral cDCs has been defined in a primary viral infection (Iwasaki, 2007; Hammad and Lambrecht, 2008). The pDCs are known as natural IFNproducing cells for their high-level production of IFN- $\alpha$ after activation, which is essential for inducing a series of antiviral IFN-stimulated genes (ISGs) and establishing an antiviral state in surrounding cells (Barchet et al., 2005; Sen and Sarkar, 2007; Zuniga et al., 2007). To a lesser extent, pDC also produce TNF- $\alpha$, IL-6 and IL-12, which are thought to influence $\mathrm{T}$ cells towards a Th1 response (Barchet et al., 2005). When porcine pDCs are exposed to viral mimics (such as ligands for TLR7/8 and TLR9) and viruses [such as pseudorabies (PrV), swine influenza virus (SIV) and transmissible gastroenteritis coronavirus (TEGV)], the expression of IFN- $\alpha$, TNF- $\alpha$, IL-2, IL-6, and IFN- $\gamma$ is significantly stimulated; however, production of IL-12 is only stimulated by the viral mimic and not viruses themselves. Significantly, the production of all of the aforementioned cytokines was not observed when pDCs were exposed to PRRSV, and IL-8 production was not responsive to both PRRSV and SIV (Calzada-Nova et al., 
2010a). A small number of viruses, which include measles virus (MV), human RSV A2 strain and classical swine fever virus (CSFV), are able to infect DCs and subvert type I IFN synthesis and/or signaling to some extent (Table 1). In this regard, PRRSV is capable of infecting DCs, primarily monocyte-derived DCs (mDCs, representing mostly cDCs) but not lung DCs. Infection of mDCs by PRRSV significantly suppresses IFN- $\alpha$ but not IFN- $\beta$ production (Loving et al., 2007). PRRSV does not infect pDCs and the presence of either live or inactivated PRRSV did not induce IFN- $\alpha$ (Calzada-Nova et al., 2010b). In addition, PRRSV also inhibits the production of some pro-inflammatory cytokines including TNF- $\alpha$ and IL- 6 but not IL-8 stimulated by a TLR9 agonist (Calzada-Nova et al., 2010a). However, CSFV-infected porcine pDCs had suppressed IFN- $\alpha$ production without inhibition of other cytokines (Carrasco et al., 2004). This suggests that the production and action of type I IFNs are primary innate antiviral responses targeted by multiple viruses for successful infection, whereas modulation of other innate immune responses are complementary for disease development (Table 1).

\section{Cell-based viral recognition mechanisms}

As illustrated in Figure 2, the innate immune system, similar to its adaptive counterpart, comprises both afferent and efferent arms to discriminate and kill pathogens (Beutler, 2004). In this context, animal cells use various receptors to perceive viral infections by recognizing pathogen-associated molecular patterns (PAMPs) culminating in the induction of antiviral responses (Pichlmair and Reis e Sousa, 2007). Prominent among these receptors are TLRs, which are vertebrate homologues revealed and named after Drosophila Toll receptors (West et al., 2006; Takeuchi and Akira, 2007). TLRs are critical for innate immune recognition and for inducing immune responses to most microbial infections (Beutler, 2004; West et al., 2006). Mammalian genome projects reveal that each mammalian species has approximately 10 TLRs, which are functional for detection of a multitude of molecular ligands derived from various microorganisms (West et al., 2006; Gay and Gangloff, 2007). Six of these TLRs have been instrumental in the response to viral infection through sensing viral components (Akira et al., 2006; Pichlmair and Reis e Sousa, 2007; Takeuchi and Akira, 2007). Among them, TLR2 and TLR4, hinged on the cell cytoplasmic membrane, recognize several viral proteins (Akira et al., 2006; Pichlmair and Reis e Sousa, 2007; Takeuchi and Akira, 2007). The functional group of TLR3, TLR7, TLR8 and TLR9 sense viral nucleic acid, either virus-derived RNA or DNA molecules (Gay and Gangloff, 2007; Forsbach et al., 2008). Accordingly, these nucleic acid-sensing TLRs are responsive mainly in acidified intracellular compartments including late endosomes and lysosomes, where most

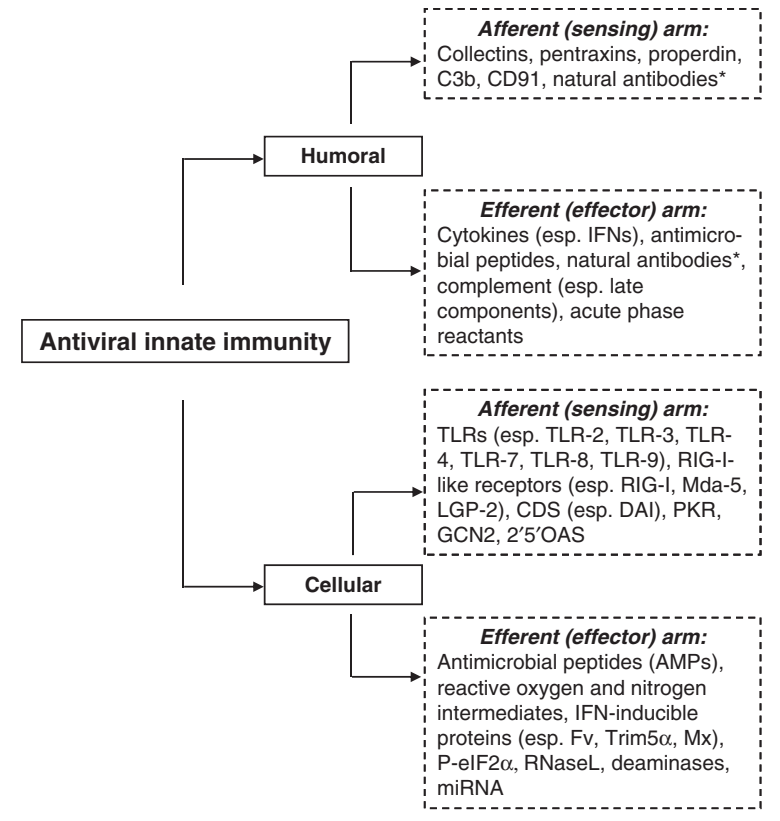

Fig. 2. Afferent and efferent arms of the innate antiviral immune response. Examples of humoral and cellular components of innate antiviral immune responses are indicated. *Natural antibodies belong to the 'innate' aspect of specific immunity. Abbreviations: CDS, cytosolic DNA sensor; DAI, DNA-dependent activator of IFN-regulatory factors; GCN2, general control nonderepressible-2; LGP-2, laboratory of genetics and physiology 2; Mda-5, melanoma differentiation-associated antigen 5; 2' $5^{\prime} \mathrm{OAS}, 2^{\prime}, 5^{\prime}$-oligoadenylate synthetase; PKR, protein kinase R; RIG-I, retinoic acid-inducible gene I; TLR, Toll-like receptor; TRIM5 $\alpha$, tripartite motif protein.

viruses undergo a de-coating process in infection routes (Pichlmair and Reis e Sousa, 2007). Besides TLR-mediated viral recognition, mainly in endosomal or lysomal compartments, animal cells also bear viral recognition and signaling mechanisms in the cytosol, where most viruses are obligated to carry out their entire or part of their infectious cycles (Pichlmair and Reis e Sousa, 2007). Four cytosol pattern recognition receptors (PRRs), including retinotic acid inducible gene I protein (RIG-I), melanoma differentiation factor-5 (Mda5) and laboratory of genetics and physiology-2 (LGP2), recognize virus derived RNA, as well as a cytosol dsDNA sensor named DNA-dependent activator of IFN regulatory factors (IRFs) (DAI), have been collectively termed RIG-I-like receptors (RLRs) (Lee and Kim, 2007; Pichlmair and Reis e Sousa, 2007; Takaoka et al., 2007). These cytosol receptors recognize distinct molecular patterns of virus-derived nucleic acids and signal the production of innate immune IFNs including types I and III IFNs (Takaoka and Yani, 2006, 2007; Onoguchi et al., 2007). Detailed information about the receptor ligand specificity and antiviral signaling transduction has been reviewed elsewhere (Akira et al., 2006; Onoguchi et al., 2007; Pichlmair and Reis e Sousa, 2007; Takeuchi and Akira, 2007; Takaoka et al., 2007). 
TLRs are conserved in pigs as indicated from gene sequences of porcine TLR1-11 (Shinkai et al., 2006a, 2006b; Sang et al., 2008a and unpublished data). In addition, porcine RIG-I and Mda5 of RLRs and the related adaptor protein of IFN- $\beta$ promoter stimulator 1 (IPS-1) have been identified (Wang et al., 2008; Kojima-Shibata et al., 2009). Pertaining to PRRSV infection, RNA helicase RIG-I has been shown to have differential expression in PRRSV infected tissues (Zhang et al., 2000). We have shown that transcripts of TLR3, TLR7 and TLR9 are significantly stimulated in PRRSV infected lungs and macrophages by the North American type 2 PRRSV (Sang et al., 2008a, b and unpublished data). Using RNA library deep sequencing, Xiao et al. (2010a, b) recently showed that multiple TLRs, RIG-I and Mda5 are stimulated by an emerged sub-strain of highly virulent Chinese-type PRRSV, but no stimulation of TLR3 was reported. It is not clear whether the highly virulent Chinese-type virus has a mechanism to suppress TLR3 gene transcription. However, we know that suppression of TLR3 expression increases PRRSV replication and infection in porcine cells (Sang et al., 2008b). The antagonism of PRRSV to inactivate the RIG-I-adaptor protein (i.e. IPS-1) and to reduce the activation of TLR3-adaptor protein (TRIF) has been demonstrated in a PRRSV-permissive monkey kidney cell line (MARC-145) (Luo et al., 2008). Thus, accumulated evidence shows that PRRSV has evolved to deviate porcine cells from perceiving and transmitting antiviral signaling before the production of antiviral effectors (Figure 3) (Luo et al., 2008; Sang et al., 2008b; Xiao et al., 2010a, b).

\section{Type I IFNs and other antiviral effectors in innate immunity}

Major classes of innate immune effectors are listed in Figure 2 and extensively reviewed elsewhere (Beutler, 2004; Klotman and Chang, 2006; Takaoka and Yanai, 2006; Lehrer, 2007; Umbach and Cullen, 2009; Hartshorn, 2010). Two major groups of innate immune effectors, type I IFNs and antimicrobial peptides (AMPs), and their role in antiviral responses will be discussed here. Type I IFNs are prominent in eliciting antiviral responses, and comprise several subtypes in mammals: IFN- $\alpha$, IFN- $\beta$, IFN- $\varepsilon$, IFN- $\omega$ and IFN-א (Pestka, 2007). Humans have multiple IFN- $\alpha$ s, and single members of IFN- $\beta$, IFN- $\varepsilon$, IFN$\kappa$ and IFN- $\omega$ (Takaoka and Yanai, 2006). Additional type I IFNs include IFN- $\delta,-\tau$ and $-\zeta$ (limitin), which are only detected in pigs and cattle (IFN- $\delta$ ), ruminants (IFN- $\tau$ ) and mice (IFN- $\zeta$ ) (Takaoka and Yanai, 2006).

In pigs, type I IFNs consist of multiple IFN- $\alpha$, IFN- $\delta$ and IFN- $\omega$ like molecules, such as porcine IFN- $\alpha$, which are encoded by as many as 17 functional genes (Sang et al., 2010a) (Table 2). In addition, pigs have single gene loci encoding each of IFN- $\beta$, IFN- $\varepsilon$ and IFN-K (Artursson et al., 1992; Sang et al., 2010a). In most mammalian species,

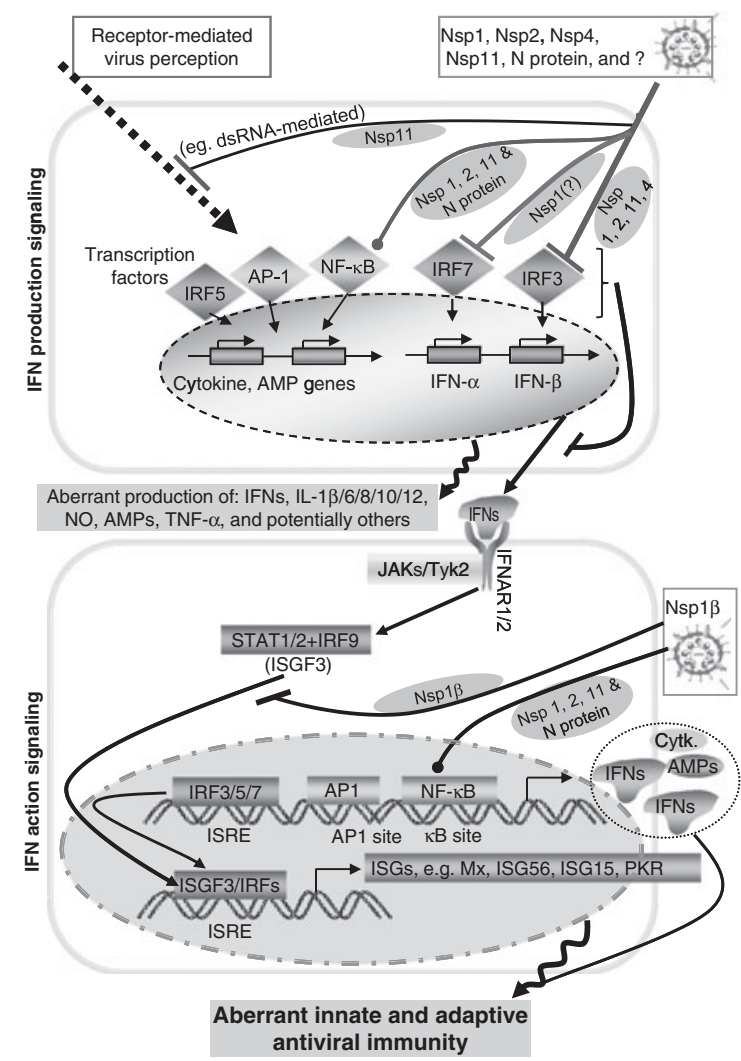

Fig. 3. Interactions between PRRSV and porcine innate immunity. PRRSV, via non-structural proteins (Nsp) or nucleocapsid $(\mathrm{N})$ protein, alter antiviral signaling through suppression of upstream virus perception of type I IFN production and action. Major virus-targeting factors include transcription factors that mediate the production/action of type I IFN and other innate immune antiviral effectors such as inflammatory cytokines and antimicrobials. Lines with blunt heads indicate suppression and lines with ball heads indicate suppression or activation. Abbreviations: AMP, antimicrobial peptide; AP-1, activator protein 1; Cytk, cytokine; IFN, interferon; IFNAR, IFN- $\alpha$ receptor; IRF, IFNregulatory factor; ISG, IFN-stimulated gene; ISRE, IFNstimulated response element; JAK/Tyk2, Janus kinase/ tyrosine-protein kinase $2 ; \mathrm{NF}-\kappa \mathrm{B}$, nuclear factor $\kappa \mathrm{B}$.

ubiquitously expressed IFN- $\alpha / \beta$ are among the most studied subtypes in antiviral responses. Although less extensively studied, the tissue-/cell-specific expressed subtypes, such as IFN- $\omega$ in various leukocytes, IFN- $\delta / \varepsilon$ in female reproductive tissues and IFN- $\kappa$ in epidermal keratinocytes, are potently induced by viral infection in these cell types and confer antiviral states on uninfected cells (Takaoka and Yanai, 2006; Pestka, 2007). Using a real-time RT-PCR array, we have detected significant expression of multiple-type IFN genes in porcine skin, intestine, lymph nodes, spleen and testis. For example, in skin, 15 IFN genes belonging to all subclasses are highly expressed, likely contributing to the skin's antiviral role as protection from repetitive exposure to viral attacks (Table 2). IFNs, except for subclass IFN- $\alpha$, are highly expressed in intestine (10 genes) and lymph nodes 
Table 2. Porcine IFN family members and gene candidates, receptors, number of amino acids, and major expression pattern

\begin{tabular}{|c|c|c|c|c|c|}
\hline Type & Subtype & $\begin{array}{l}\text { Gene locus and } \\
\text { (number of subtypes) }\end{array}$ & Receptor & $\begin{array}{l}\text { Number of } \\
\text { amino acids }\end{array}$ & Major expression pattern \\
\hline \multirow[t]{9}{*}{ I } & IFN- $\alpha$ & $1 q 22-q 27\left(17\right.$ and $\left.2 \psi^{d}\right)$ & \multirow{9}{*}{$\begin{array}{l}\text { IFNAR1 } \\
\text { IFNAR2 }\end{array}$} & $181-189$ & Ubiquitous expression \\
\hline & IFN- $\alpha \omega$ & $1 q 22-q 27(1)$ & & 185 & Skin \\
\hline & IFN- $\beta$ & $1 q 23-q 27(1)$ & & 186 & Ubiquitous expression \\
\hline & IFN- $\delta^{a}$ & SSA1 (11) & & $153-184$ & $\begin{array}{l}\text { Trophoblast, skin, MLN, Intestine, } \\
\text { skin, MLN and uterus }\end{array}$ \\
\hline & IFN- $\varepsilon$ & SSA1 (1) & & 193 & Multiple tissues, skin and MLN \\
\hline & IFN- $\omega$ & SSA1 ( 7 and $2 \psi)$ & & $176-190$ & Intestine, MLN \\
\hline & IFN-א & SSA10 (1) & & 207 & Skin \\
\hline & IFN- $\tau^{b}$ & NA & & & \\
\hline & $\mathrm{IFN}-\zeta^{\mathrm{C}}$ & NA & & & \\
\hline II & IFN- $\gamma$ & $5 p 1.2-q 1.1 /(1)$ & IFNGR1/IFNGR2 & 166 & Activated T cells, NK-cells \\
\hline \multirow[t]{3}{*}{ III } & IFN- $\lambda 1$ (IL-29) & $?$ & \multirow[t]{3}{*}{ IL-28R $\alpha / I L-10 R 2$} & 191 & Ubiquitous expression \\
\hline & IFN- $\lambda 2($ IL-28A) & NA & & NA & Intestine and MLN \\
\hline & IFN- $\lambda 3($ IL-28B) & SSA14 & & 195 & \\
\hline
\end{tabular}

Modified from Chang et al. (2006), Takaoka and Yanai (2006), and Sang et al. (2010a, b). Found only in apigs and cattle, ${ }^{b}$ ruminants, or ${ }^{c}$ mice. ${ }^{d} \psi$, pseudo genes; MLN, mesenteric lymph nodes; NA, not applicable.

(9 genes). In contrast, bone marrow cells and liver showed a relatively weaker expression pattern of type I IFNs. Relative to subtype differences, IFN- $\alpha 1 / 8 / 12$ and IFN- $\beta$ are detected in all tested tissues; and porcine IFN$\delta 5 / 6 / 8$, IFN- $\omega 1 / 2 / 3$ and single-subtype subclasses IFN- $\varepsilon$ and IFN- $\kappa$ are detectable in most tested tissues. IFN- $\alpha \omega$, a unique subtype only found in pigs and cattle, is highly expressed in porcine skin, but detectable in the intestine, lymph nodes and spleen, implying an intensification of IFN response (Sang et al., 2010a) (Table 2).

Type I IFNs are central cytokines in antiviral innate immunity. The local production of type I IFNs around infection sites comprises a major antiviral barrier to inactivate viruses and limit virus spreading. Natural or modified IFN peptides have been well documented for various IFN-based antiviral therapies, which are effective against many viral diseases including viral hepatitis, HIV and SARS infections (Haagmans and Osterhaus, 2006; Deutsch and Hadziyannis, 2008; Sulkowski and Benhamou, 2007). Type I IFNs, produced during the early phase of virus-cell interaction, not only activate antiviral responses via autocrine mechanisms, but also diffuse or transmit systemically to induce an antiviral state in surrounding and distal cells. The induction of an antiviral state, which involves the suppression of cellular metabolic levels of protein synthesis and the profound expression of genes encoding antiviral products (Haller and Weber, 2007; Zuniga et al., 2007), is critical for developing effective immune protection against viral infections. Type I IFNs collectively induce antiviral responses through a common receptor composed of two subunits, IFN- $\alpha / \beta$ receptor (IFNAR)-1 and IFNAR-2 (Table 2). However, the efficacy for induction of antiviral responses is different among subtypes and even between members belonging to the same subtype. For example, human IFN- $\alpha$ s vary in their ability to activate human NK cells, IFN- $\beta$ shows more potency than IFN- $\alpha 2$ in inhibition of monocyte proliferation (García-Sastre and Biron,
2006; Takaoka and Yanai, 2006). Functional differences among type I IFNs are related to their diverse affinities and kinetics in interaction with IFNAR subunits. In addition, differential expression of each type I IFN and receptor subunits with regard to tissue/cell types also contributes to distinct regulation of antiviral responses (Uzé et al., 2007).

Porcine IFNs have varying levels of activity against PRRSV and other viruses in cells. In general, most subtypes of the IFN- $\alpha$ subclass are highly active against PRRSV; however, other subclasses including IFN- $\beta$, IFN- $\delta$, IFN- $\varepsilon$ and IFN- $\kappa$, are not (Sang et al., 2010a). Studies indicate that IFN- $\alpha$ subtypes are mainly down-regulated in response to PRRSV infection (Loving et al., 2007; Jung et al., 2009; Sang et al., 2010a). This suggests that IFN- $\alpha$ subtypes, not IFN- $\beta$, should receive emphasis in the modulation of porcine anti-PRRSV innate immunity. This viewpoint is supported by findings showing that PRRSV isolates differ in their sensitivity to IFN- $\alpha$ suppression (Lee et al., 2004) and by the recent identification of PRRSVdiminishing IFN- $\alpha$ production through intervening signal transducers and activators of transcription (STAT)1-IRF7 signaling in pDCs (Calzada-Nova et al., 2010b).

The interaction of type I IFNs with their receptors leads to the activation of transcription factors of STATs by two IFNAR-associated kinases. The activated STAT1, STAT2 and IRF9 form an activator complex of IFN-activated trimeric transcription factor, ISGF3, which interacts with the IFN-stimulated response element (ISRE) in promoters of ISGs to prompt transcription. Hundreds of ISGs have direct virus targeting functions (e.g. MxA, RNase L and RNA deaminases), amplifying antiviral resistance (e.g. PKR, 2' $5^{\prime} \mathrm{OAS}$, and type I IFN themselves), and sequestration of cellular metabolic processes to repress virus replication (e.g. PKR-mediated arrest of protein synthesis) (Sen and Sarkar, 2007). It is notable that most notorious viruses have improved their capability to evade or subvert the IFN system for their own benefit. Extensive reviews 
(Iannello et al., 2006; Haller and Weber, 2007; Loo and Gale, 2007) on this topic indicate that a collection of virusderived factors may interfere with IFN production and/or IFN-action pathways (Table 1).

In addition to type I IFNs, three type III IFNs (IFN$\lambda 1-\lambda 3$, also known as IL-29, IL-28A and IL-28B, respectively), have been identified. Accumulated evidence indicates that type III IFNs are induced through similar signal transduction pathways as type I IFNs (Ank and Paludan, 2009). For example, activation of signaling pathways mediated by TLR3 and RIG-I, which has been well characterized to induce IFN- $\alpha / \beta$ production, also induces type III IFNs in murine and human cells (Ank and Paludan, 2009). The antiviral activity of human type III IFNs has been associated with multiple viral infections including those caused by hepatitis $\mathrm{C}$ virus, influenza A virus and cytomegalovirus (Ank et al., 2006; Ank and Paludan, 2009). However, type III IFNs are distinct from type I IFNs in their gene and protein structures as well as their receptors and expression patterns. For example, genes of all known mammalian type III IFNs have multiple exons (usually five) in contrast to the singleexon genes for type I IFNs (Fox et al., 2009). The protein structure of human IFN- $\lambda 3$ more closely resembles IL-22 of the IL-10 cytokine family rather than other IFNs (Gad et al., 2009). Critically, type III IFNs act through cell receptors of the IL-28RA/IL-10R2 complex rather than the IFNAR1/IFNAR2 receptors of the type I IFNs (Kotenko et al., 2003; Sheppard et al., 2003). In addition, type III IFNs and their receptors are prominent in epithelial tissues, suggesting their involvement in epithelial antiviral immunity (Ank and Paludan, 2009). Thus, type III IFNs comprise a group of newly identified antiviral cytokines that are functionally similar to type I IFNs and elicit firstline antiviral responses, especially in epithelial cells. We have shown that pigs have at least two type III IFNs, IFN$\lambda 1$ and IFN- $\lambda 3$, and that both exert similar but lower activity than IFN- $\alpha / \beta$ against PRRSV in cells (Sang et al., 2010b). Non-IFN cytokines, chemokines and AMPs are other groups of important innate immune effectors (Figure 2) (Beutler, 2004; Klotman and Chang, 2006; Pancer and Cooper, 2006; Takaoka and Yanai, 2006; Lehrer, 2007; Sang and Blecha, 2008; Umbach and Cullen, 2009; Hartshorn, 2010). The innate immune roles of cytokines and chemokines have been emphasized in aspects of pro-/anti-inflammation and attraction/activation of immune cells, which are important for overall immune responses. Although the antiviral activity of AMPs has been known for some time (Daher et al., 1986), research in this area has recently intensified (reviewed in Klotman and Chang, 2006; Lehrer, 2007). We, along with others, have demonstrated that PRRSV infection suppresses the expression of AMPs and general antimicrobial activity especially in the lungs of young pigs (Sang and Blecha, 2009; Sang et al., 2009; Jung et al., 2010). Direct inactivation of PRRSV by porcine $\beta$-defensin (pBD) 3 and protegrin 4 has also been demonstrated in vitro (Sang et al., 2009). Animal AMPs exert antiviral activity by distortion of virion glycoproteins and lipid membranes in enveloped viruses, and by impeding viral entrance into host cells. Other mechanisms of AMP antiviral activity have also been proposed, including down regulation of viral receptors (e.g. hBD3 for CXCR4 of receptor to HIV-1) (Feng et al., 2006), modulation of cellular antiviral signaling (e.g. HNP-1 for PKC signaling) (Salvatore et al., 2007) and potentiating adaptive immunity (Klotman and Chang, 2006). In addition, other carbohydrate binding proteins such as collectins, including Mannan-binding lectin (MBL), surfactant protein A (SP-A), surfactant protein D (SP-D) and ficolin, have been shown to participate in innate immune responses exerting antiviral activity. Recently, a porcine plasma ficolin was reported to have inhibitory activity against PRRSV replication in a $\mathrm{N}$-acetylated glycan-dependent manner (Keirstead et al., 2008). These findings indicate that intervening in the interaction between sugar moieties of the viral envelope and host cells is a target for innate immune molecules to inhibit PRRSV infection (Klotman and Chang, 2006; Lehrer, 2007).

\section{The interaction of PRRSV and porcine innate immunity}

\section{Aberration of porcine innate immunity by PRRSV}

Two decades ago, initial reports of PRRSV occurred almost simultaneously in the U.S. and central Europe. These viruses were defined as type 1 European-PRRSV and type 2 North American-PRRSV. PRRS continues to be the most significant worldwide swine disease and a persistent challenge in both immunology and vaccinology (Kimman et al., 2009; Darwich et al., 2010; Huang and Meng, 2010; Murtaugh et al., 2010). PRRSV evolves at a high mutation rate compared with other RNA viruses and has the potential to subvert host innate immune responses by various means. These include intervening in cell recognition of the virus, diverting antiviral cytokine (especially type I IFNs, IL-1, IL-10 and TNF- $\alpha$ ) production and action, directing cytolysis, reducing antigen presentation activity and suppressing phagocytic and microbicidal activity (Darwich et al., 2010; Thanawongnuwech and Suradhat, 2010; Yoo et al., 2010). The innate immune aberration could further contribute to inefficiently bridging adaptive immunity, which in cooperation with other diverting mechanisms on adaptive immunity, causes overall immune inefficacy to PRRSV and other co-infections (Darwich et al., 2010).

Collectively, data show that PRRSV infection leads to an increase of most if not all viral sensing TLRs in the lungs or lymphoid organs, including TLR2, TLR3, TLR4, TLR7, TLR8 and TLR9 (Sang et al., 2008b; Liu et al., 2009; Xiao et al., 2010a, b). The increased TLR transcripts of TLR7 and TLR9 may last for at least 1-week post infection 
(Xiao et al., 2010a, b) with TLR2 and TLR4 returning toward the basal levels after 3-days post infection. It appears that upregulation of TLR3 is conditiondependent. The in vitro infection of PAMs and mDCs (Sang et al., 2008b; Chaung et al., 2010) or in vivo infection of fetal lungs (Sang et al., 2008b) fails to increase or even transiently decrease TLR3 expression. Similarly, no significant increase of TLR3 and TLR8 expression was found in lungs of pigs infected with the highly virulent Chinese-type PRRSV (Xiao et al., 2010a, b). Expression of cytosol virus sensing receptors of RIG-I and Mda5 is also significantly stimulated in lungs infected by type 2 PRRSV (Xiao et al., 2010a, b). The increase in these virus-sensing receptors may potentially lead to antiviral responses. Overexpression of TLR3 resulted in enhancement and reduction of TLR3 suppressed anti-PRRSV activity in virusinfected cells (Sang et al., 2008b). Although it is unknown whether PRRSV has a mechanism to reduce the expression of these receptors, the activation of TLR7 and TLR9 signaling in pDCs appears inhibited by the presence of PRRSV (Calzada-Nova et al., 2010a). The implication of data using MARC-145 cells is that PRRSV may interfere with adaptor proteins to suppress both RLR- and TLR3mediated stimulation of IFN production (Luo et al., 2008; Miller et al., 2009). Notably, the acute activation of these receptor-mediated signaling pathways also leads to increased production of pro-inflammatory cytokines and chemokines as well as activation of the complement systems; this process is thought to be the cause of pneumonia in PRRS cases (Xiao et al., 2010a). In addition, the inflammatory response could be amplified in the presence of bacterial endotoxin (Qiao et al., 2011) or lowavidity immune complex (Monsalvo et al., 2011) to promote macrophages skewing to the M2 status (Stout et al., 2009). Human M2 macrophages show higher expression of CD163, heparin sulfate and IL-10 (Cassol et al., 2010); similar responses in pigs could potentially exacerbate PRRSV infection (Patton et al., 2009; Welch and Calvert, 2010).

The production and action of the type I IFN system are hallmarks of innate antiviral immunity. Earlier reports have shown that pigs infected with PRRSV produce very low levels of type I IFNs. Exogenous application of IFN- $\alpha$ could control the virus infection in porcine PAMs and MARC-145 cells (Albina et al., 1998; Buddaert et al., 1998). Studies by Lee et al. (2004) showed that different field isolates and even virus quasi-species rescued from individual plaque clones of the same isolate vary in their ability to induce IFN- $\alpha$ and susceptibility to IFN- $\alpha$ treatment. PRRSV also infects mDCs and significantly suppresses type I IFN production of the IFN- $\alpha$ subtype but not the IFN- $\beta$ subtype (Loving et al. 2007). Extensive analysis of porcine type I IFN profiles indicates that pigs have as many as 39 functional genes including 17 IFN- $\alpha$, $11 \mathrm{IFN}-\delta, 7$ IFN- $\omega$, as well as a single member of each of the IFN- $\alpha \omega$, IFN- $\beta$, IFN- $\varepsilon$ and IFN- $\kappa$ subtypes (Sang et al., 2010a). Comparative antiviral analyses in both porcine
PAMs and MARC-145 cells indicate that most IFN- $\alpha$ and IFN- $\alpha \omega$ have higher activity against PRRSV infection than do other subtype members (Sang et al., 2010a).

Determined by the stability of the ternary IFN-receptor complex, type I IFNs biological activities proceed in two directions, antiviral activity and immunomodulatory activity (Uzé et al., 2007; Kalie et al., 2008). Whereas IFN- $\alpha$ subtypes generally have more antiviral potency, IFN- $\beta$ displays more immunomodulatory activity such as promotion of cell proliferation (Kalie et al., 2008). Recent studies have shown that IFN- $\beta$ has anti-inflammatory properties inducing IL-10 production in human mDCs (Wang et al., 2011) and regulating alternative activation of macrophages through induction of IL-4, IL-13 and IL-10 in RSV infected murine lungs (Shirey et al., 2010). Interestingly, PRRSV suppression of IFN- $\beta$ production through targeting IRF3 has been mostly observed in MARC-145 cells or experimental human cell lines (Miller et al., 2004; Luo et al., 2008; Shi et al., 2010; Chen et al., 2010a; Kim et al., 2010; Li et al., 2010; Beura et al., 2010; Song et al., 2010). These observations are not always consistent with the data from infected pigs or porcine cells (Loving et al., 2007; Genini et al., 2008). In contrast, in vivo or ex vivo tests in porcine lungs strongly support PRRSV-mediated IFN- $\alpha$ suppression in porcine lungs (Jung et al., 2009), PAMs (Albina et al., 1998; Genini et al., 2008; Patel et al., 2010), mDC (Loving et al., 2007) and pDCs (Calzada-Nova et al., 2010a, b).

Cell type difference in respect to response to PRRSV mediated IFN-suppression has recently been noted (Loving et al., 2008; Sang et al., 2010a; He et al., 2011). In addition, the suppression of IFN- $\delta$ or IFN- $\omega$ (termed SPI IFN in the reference) has also been observed (Xiao et al., 2010b; Sang, unpublished data); therefore, whether all type I IFNs are generally suppressed or differentially regulated by PRRSV in vivo to facilitate virus infection should be determined. PRRSV suppresses type I IFN signaling primarily in infected cells, as indicated by suppression of ISG15 and ISG56 in PRRSV infected MARC-145 and PAMs (Patel et al., 2010). However, exogenous application of IFNs does prevent PRRSVsuppression of IFN signaling due to the treatment of PAMs with either porcine type I, II or III IFNs, and especially IFN- $\alpha$, which induce significant anti-PRRSV activity (Rowland et al., 2001; Sang et al., 2010a, b).

PRRSV infection also diverts the production of other cytokines and antimicrobial molecules, such as AMPs and nitric oxide (NO). However, reports regarding PRRSV regulation of cytokines are quite controversial. Both increases and decreases of pro-inflammatory cytokines such as TNF- $\alpha$, IL-1 and IL- 6 , have been shown in PRRSV infected pigs and PAMs (Darwich et al., 2010). PRRSV does prevent the production of IL-8 (Calzada-Nova et al., 2010a) in pDCs but other studies have found that PRRSV induces IL-8 (Darwich et al., 2010). More extensive cytokine analyses have linked IL- $1 \beta$, IL- 8 and IFN- $\gamma$ but not IL-12 with PRRSV clearance (Lawson et al., 2010; 
Lunney et al., 2010). IL-10 is an immunosuppressive cytokine, which is up-regulated by PRRSV infection (Thanawongnuwech and Suradhat, 2010) and induces PAM permissiveness to PRRSV (Patton et al., 2009). Similar to the regulation of other cytokines, PRRSV infected pigs or cells have been shown to have either increased or decreased IL-10 production (Klinge et al., 2009; Darwich et al., 2010; Subramaniam et al., 2011). Therefore, as suggested by studies of Díaz et al. (2006) and Silva-Camp et al. (2010), PRRSV-regulation of IL-10 may be both pig- and virus-strain dependent. Studies evaluating PRRSV-suppression of antimicrobial and phagocytic activities are consistent in virus-infected lungs and PAMs, showing that, in general, PRRSV decreases the production of AMPs and NO, and suppresses the microbicidal activity of both PAMs and NK cells (Thanawongnuwech et al., 2000; Jung et al., 2009; Sang et al., 2009). PRRSV also directs cytolysis in infected PAMs and $\mathrm{mDCs}$ and cell death is prominent in activated M2 macrophages (unpublished data). The suppression of microbicidal activity and direction of cell death of innate immune cells at the cellular and molecular levels may be linked to co-infections with PRRSV.

\section{Viral mechanisms responsible for innate immune aberration}

PRRSV is an enveloped virus, which has a $\sim 15 \mathrm{~kb}$ $(+)$ ssRNA genome containing nine open reading frames (ORF). The $5^{\prime}$ end ORF1a and ORF1b encode two replicase polyproteins, pp1a and pp1b. The proteolytic ppla products self cleave into nine non-structural proteins (Nsp) (Nsp1 $\alpha, \mathrm{Nsp} 1 \beta$ and Nsp2-8), and cleave pp1b into four Nsp (Nsp9-12). The $3^{\prime}$ end seven ORFs encode four minor (GP2a, GP3, GP4 and E proteins) and three major (GP5, M and N proteins) structural proteins. Besides their essential role in viral replication, recent studies highlight the roles of the Nsp in immune modulation of innate immune effectors (Fang and Snijder, 2010; Yoo et al., 2010). Four viral Nsp have strong to moderate inhibitory effects (Nsp1 $>$ Nsp2 $>$ Nsp11 $>$ Nsp4) on IFN- $\beta$ production through inactivating IRF3, which is a key transcription factor responsible for activation of the IFN- $\beta$ promoter (Beura et al., 2010).

Nsp1 and its two autocleaved products, Nsp1 $\alpha$ and Nsp1 $\beta$, have been shown to have the highest activity inhibiting IRF3 activation (Beura et al., 2010; Yoo et al., 2010). Beura et al. (2010) indicated that Nsp1 $\alpha$ and $N s p 1 \beta$ block IRF3 nuclear translocation; however, Yoo et al. (2010) observed no blocking of Nsp1 $\alpha$ and Nsp1 $\beta$ in IRF3 nuclear translocation, and proposed a mechanism based on Nsp1 promoting degradation of the CREB (cyclic AMP response element binding)-binding protein (CBP). CBP has histone acetyltransferase activity functioning in dissociation of histones from the DNA promoter region, and the $\mathrm{CBP} / \mathrm{p} 300$ co-activators function in concert with a variety of transcription factors including STATs, NF- $\kappa \mathrm{B}$, PIAS1 and the IRF family (Yoo et al., 2010). Nsp1mediated CBP-degradation may provide a general explanation of PRRSV immune suppression via interaction with IRF3 as well as STAT2, because the decrease in STAT2 at the protein level has been reported in PRRSV-infected cells (Patel et al., 2010). In another report, both Nsp1 $\alpha$ and Nsp1 $\beta$ were shown to dramatically inhibit IFN- $\beta$ expression and Nsp1 $\beta$ also suppressed IFN signaling via inhibiting STAT1 nuclear translocation (Chen et al., 2010a). Patel et al. (2010) further demonstrated that STAT1 is not the only factor inhibited as nuclear translocation of ISGF3 (ISG factor 3, composed by STAT1/STAT2/IRF9) was also inhibited by Nsp1 $\beta$ to suppress IFN- $\alpha$ signaling in the virus-infected cells. PRRSV does not infect pDCs, but the presence of some uncharacterized viral component blocks STAT1 nuclear localization thereby reducing the availability of IRF7, which has been thought to be a mechanism for PRRSV inhibition of IFN- $\alpha$ production in pDCs (Calzada-Nova

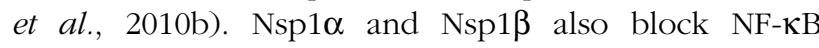
activation (Song et al., 2010), a critical transcription factor in innate immune signaling not only for antiviral responses; therefore, Nsp1 proteins may also be the viral components responsible for suppressing other cytokines and AMPs in addition to IFNs (Figure 3).

PRRSV Nsp2 represents another major immunomodulatory protein (Fang and Snijder, 2010). The region of 691-722 residues in Nsp2 has been shown to be important for virus mediation of production of pro-inflammatory cytokines including IL-1 $\beta$ and TNF- $\alpha$ (Chen et al., 2010b). Biochemically, Nsp2 belongs to the deubiquitinase superfamily; through this activity, it can interfere with the polyubiquitination process of ISG15 and IKK $\alpha$ (inhibitor of nuclear factor kappa-B kinase (NF- $\kappa \mathrm{B})$ subunit $\alpha$ ), thereby targeting the IFN response and NF- $\kappa \mathrm{B}$ signaling pathways respectively (Sun et al., 2010).

PRRSV Nsp11 also has dual roles in suppression of IFN responses (Yoo et al., 2010) and reduction of $\mathrm{NF}-\kappa \mathrm{B}$ activation (Beura et al., 2010). Nsp11 has endo-RNase activity; its suppression of IFN response may partially be due to cleavage of viral RNA patterns to dampen the binding by multiple cellular antiviral receptors including TLR3/7/8/9, RIG-I, and Mda5, thus reducing the upstream viral sensing in antiviral signaling (Yoo et al., 2010). In addition, Nsp11 has been shown to block IRF3 phosphorylation and nuclear translocation (Yoo et al., 2010), but it is unclear whether this resulted from weakened upstream signaling (i.e., diminishing dsRNA binding) or Nsp11 targeting IRF3 directly through other mechanisms.

As previously mentioned, PRRSV has been reported to strongly induce IL-10 production during the early phase of infection in pigs (Thanawongnuwech and Suradhat, 2010) and in cultured porcine PBMCs and PAMs (Yoo et al., 2010). The viral mechanism to induce IL-10 is reported to be the nucleocapsid (N) protein (Yoo et al., 2010). The N protein is a small basic protein of 123 (or 128 


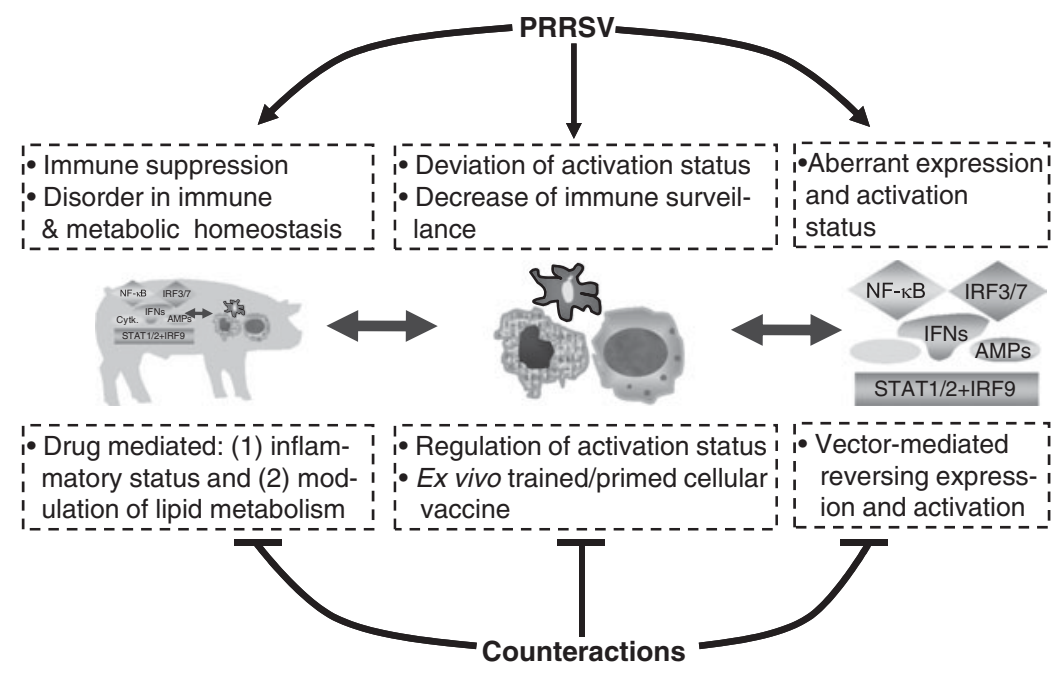

Fig. 4. Tactics to counteract PRRSV deviation of porcine innate immunity at the molecular, cellular and animal levels. Viral aberration is indicated in the top portion of the figure. Vector-based expression or suppression of the virus-aberrant antiviral effectors (or signaling molecules) may work alone or in concert with a subunit vaccine to stimulate effective anti-PRRSV protection. Innate immune cells, especially PRRSV-infected monocytic cells, are platforms to manipulate virus-aberrant cell activation status and innate immune response. In pigs, drug-based approaches to modulate inflammatory and lipid metabolic status may be feasible to alter host response to vaccination or infection.

of type I PRRSV) residues and it is the most abundant virion component and the most immunogenic protein in virus-infected pigs and cells (Music and Gagnon, 2010). The mechanism of $\mathrm{N}$ protein induction of IL-10 is unknown. Given that nucleolus-localized $\mathrm{N}$ protein interacts with several cell transfactors (Yoo et al., 2010), there is potential of the $\mathrm{N}$ protein directly targeting the IL10 gene promoter. In addition, recent evidence shows that IFN- $\beta$, produced from LPS activation of macrophages or DCs, induces IL-10 in these cells (Chang et al., 2007; Wang et al., 2011). The N protein may activate the NF- $\kappa B$ pathway to induce IFN- $\beta$ production through TLR 4 activation of NF- $\mathrm{KB}$ pathways, therefore, inducing IL-10 stimulation and NF- $\kappa \mathrm{B}$ activation with LPS-TLR4 signaling (Chang et al., 2007; Wang et al., 2011). This assumption is supported by the understanding that $\mathrm{N}$ protein does activate NF- $\mathrm{KB}$ in MARC- 145 cells and the region between residue $30-73$ of $\mathrm{N}$ protein is essential for this function (Luo et al., 2011), and TLR4 is induced in PRRSV infected pigs (Xiao et al., 2010a). Integrating the points of $\mathrm{N}$ protein activation of $\mathrm{NF}-\kappa \mathrm{B}$, LPS-TLR 4 mediated IFN- $\beta$ production and IL-10 induction by IFN$\beta$ explains several controversial observations such as the induction/no-induction of IFN- $\beta$ and IL-10 as well as the activation/suppression of NF- $\mathrm{KB}$ in PRRSV infected pigs or cells. Therefore, the consequent levels of IFN- $\beta$ and IL-10 (and probably other innate immune effectors too) are not only dependent on PRRSV infection but also the activation of LPS-TLR4 signaling by some bacterial endotoxins; and the suppression or activation of $\mathrm{NF}-\kappa \mathrm{B}$ signaling should be variable according to the intensity and tempo between the $\mathrm{N}$ protein's positive and Nsp's negative effects. In summary, innate immune deficiency caused by PRRSV infection complicates the viral disease creating a complex syndrome. The challenge faced is not only from the small virus per se, but mostly, if not always, from the interaction of other opportunistic infections in a host with a disruption in homeostasis.

\section{Concluding remarks}

In Figure 4, we briefly summarize our understanding of PRRSV diversion of innate immunity at the levels of the animal, cell and molecule. We propose that through viral parasitization and interaction to deviate the expression and/or activation states of innate immune molecules, PRRSV alters the environment for development/activation of innate immune cells, and particularly dominates the functional status of monocytic cells including tissue macrophages and circulating DCs by direct infection or standby suppression in pDCs. The viral aberration of innate immunity has been shown at the cellular level in two aspects. Firstly, the skewing or adapting of innate immune cells to the status of anti-inflammation and immunosuppression at the early phase of infection, such as the M2 status of macrophages, which are observed to be more permissive to PRRSV infection than M1 cells (Patton et al., 2009; Sang, unpublished data). Secondly, there is suppression of immune surveillance including dampened microbicidal and antigen processing activity in DCs and macrophages (Sang et al., 2009; Jung et al., 2009; Thanawongnuwech and Suradhat, 2010).

Pertaining to the characteristics of tissue- or cell-tropism, the primary sites of PRRSV infection, including reproductive and pulmonary tissues, contain monocytic cells that are naturally inclined to a M2 or immunosuppressive 
status, especially those in the reproductive tissues with immune privilege. This viewpoint suggests that PRRSV has evolved to adapt rather than skew innate immune cells to establish an infection at the animal level, and the high-virulence PRRSV strains, which cause significant host mortality because of the dramatic inflammatory response (Xiao et al., 2010a), are unique cases of unsuccessful parasitization. Therefore, the suppression of $\mathrm{M} 1$ activation especially antiviral status induced by type I IFNs in innate immune cells during the early phase of infection might be a key for designing counteractions to target PRRSV infection at both cell and animal levels. However, unlike in ex vivo cells, time and intensity are more critical for the success of inflammatory and immune regulation in vivo (Figure 4). In this line, some herbal therapies, which have been shown effective in treatment of inflammatory symptoms in SARS (Leung, 2007) and pandemic influenza (Ge et al., 2010), are worth evaluating in PRRSV pandemics. In addition, lipid metabolites such as sphingosine-1-phosphate (S1P) have been known for critical regulation of inflammation and immune cell recruitment/activation (Spiegel and Milstien, 2011). Several recent studies elegantly linked lipid metabolism to immune status of macrophages (Im et al., 2011), T cells and DCs (Herber et al., 2010), as well as cytokine storms in influenza-infected lungs (Teijaro et al., 2011). It will be informative to examine the role of modulators/metabolites of lipid metabolism in regulation of inflammatory and immune status during PRRSV infection and vaccine development.

Finally, the development of vaccines to induce effective protection against heterologous PRRSV isolates should be focused at the cellular and molecular levels. To this end, the adjuvant mechanisms underlying innate immunity (Coffman et al., 2010) should be considered in respect to PRRSV-diverted innate immune components as reviewed above. Positive effects have been obtained in studies with expression of IFN- $\alpha$ alone (Brockmeier et al., 2009) or conjugated expression of innate immune effectors including CD40L (Cao et al., 2010), GM-CSF (Wang et al., 2009) and HSP70 (Li et al., 2009b) with the viral epitopes using adenovirus vectors. In addition, several studies using RNA interference techniques have shown promise in suppression of PRRSV infection in both cells and pigs (Lu et al., 2006; Li G et al., 2009a), implying that miRNAmediated antiviral mechanisms, which have been found in regulation of HCV and HIV infection (Skalsky and Cullen, 2010), could be also functional in PRRSV-host interaction. Viruses are dependent on cell metabolism and genome-wide screening of host factors critical for host-viral interaction has revealed a large number of candidates belonging to metabolic pathways besides immune genes (Karlas et al., 2010; König et al., 2010). To this end, it is likely that aberration of lipid metabolism is a major consequence in PRRSV-host interaction (Xiao et al., 2010b) and the regulation of lipid signaling has potential to prime activation status and immune surveillance of innate immune cells. In summary, to induce ideal anti-PRRSV protection, strategies should be considered for targeting innate immune components to counteract viral replication/spreading and subversion of immunity as well as to mitigate immune pathology from excessive/persistent activated innate immune responses (Figure 4).

\section{Acknowledgments}

We thank Kansas Agricultural Experiment Station for their contribution under number 12-112-J.

\section{References}

Afonso CL, Piccone ME, Zaffuto KM, Neilan J, Kutish GF, Lu Z, Balinsky CA, Gibb TR, Bean TJ, Zsak L and Rock DL (2004). African swine fever virus multigene family 360 and 530 genes affect host interferon response. Journal of Virology 78: $1858-1864$

Albina E, Carrat C and Charley B (1998). Interferon-alpha response to swine arterivirus (PoAV), the porcine reproductive and respiratory syndrome virus. Journal of Inter feron and Cytokine Research 18: 485-490.

Akira S, Uematsu S and Takeuchi O (2006). Pathogen recognition and innate immunity. Cell 124: 783-801.

Ank N and Paludan SR (2009). Type III IFNs: new layers of complexity in innate antiviral immunity. BioFactors 35 82-87.

Ank N, West H and Paludan SR (2006). IFN-lambda: novel antiviral cytokines. Journal of Interferon and Cytokine Research 26: 373-379.

Appelberg R (2007). Neutrophils and intracellular pathogens: beyond phagocytosis and killing. Trends in Microbiology 15: 87-92.

Artursson K, Gobl A, Lindersson M, Johansson M and Alm G (1992). Molecular cloning of a gene encoding porcine interferon-beta. Journal of Interferon Research 12: 153-160.

Barchet W, Cella M and Colonna M (2005). Plasmacytoid dendritic cells - virus experts of innate immunity. Seminars in Immunology 17: 253-261.

Bauhofer O, Summerfield A, Sakoda Y, Tratschin JD, Hofmann MA and Ruggli N (2007). Classical swine fever virus Npro interacts with interferon regulatory factor 3 and induces its proteasomal degradation. Journal of Virology 81: 3087-3096.

Beisswenger C and Bals R (2005). Antimicrobial peptides in lung inflammation. Chemical Immunology and Allergy 86: 5571.

Beura LK, Sarkar SN, Kwon B, Subramaniam S, Jones C, Pattnaik AK and Osorio FA (2010). Porcine reproductive and respiratory syndrome virus nonstructural protein 1beta modulates host innate immune response by antagonizing IRF3 activation. Journal of Virology 84: 1574-1584.

Beutler B (2004). Innate immunity: an overview. Molecular Immunology 40: 845-859.

Borghetti P, Saleri R, Ferrari L, Morganti M, De Angelis E, Franceschi V, Bottarelli E and Martelli P (2011). Cytokine expression, glucocorticoid and growth hormone changes after porcine reproductive and respiratory syndrome virus (PRRSV-1) infection in vaccinated and unvaccinated naturally exposed pigs. Comparative Immunology, Microbiology and Infectious Diseases 34: 143-155. 
Borregaard N, Sørensen OE and Theilgaard-Mönch K (2007). Neutrophil granules: a library of innate immunity proteins. Trends in Immunology 28: 340-345.

Bousse T, Chambers RL, Scroggs RA, Portner A and Takimoto T (2006). Human parainfluenza virus type 1 but not Sendai virus replicates in human respiratory cells despite IFN treatment. Virus Research 121: 23-32.

Brockmeier SL, Lager KM, Grubman MJ, Brough DE, Ettyreddy D, Sacco RE, Gauger PC, Loving CL, Vorwald AC, Kehrli Jr ME and Lehmkuhl HD (2009). Adenovirus-mediated expression of interferon-alpha delays viral replication and reduces disease signs in swine challenged with porcine reproductive and respiratory syndrome virus. Viral Immunology 22: 173-180.

Brukman A and Enquist LW (2006a). Suppression of the interferon-mediated innate immune response by pseudorabies virus. Journal of Virology 80: 6345-6356.

Brukman A and Enquist LW (2006b). Pseudorabies virus EP0 protein counteracts an interferon-induced antiviral state in a species-specific manner. Journal of Virology 80: 1087110873.

Buddaert W, Van Reeth K and Pensaert M (1998). In vivo and in vitro interferon (IFN) studies with the porcine reproductive and respiratory syndrome virus (PRRSV). Advances in Experimental Medicine and Biology 440: 461-467.

Calzada-Nova G, Schnitzlein W, Husmann R and Zuckermann FA (2010a). Characterization of the cytokine and maturation responses of pure populations of porcine plasmacytoid dendritic cells to porcine viruses and toll-like receptor agonists. Veterinary Immunology and Immunopathology 135: 20-33.

Calzada-Nova G, Schnitzlein WM, Husmann RJ and Zuckermann FA (2010b). North American porcine reproductive and respiratory viruses inhibit type I interferon production by plasmacytoid dendritic cells. Journal of Virology $\mathbf{8 5}$ 2703-2713.

Cao J, Wang X, Du Y, Li Y, Wang X and Jiang P (2010). CD40 ligand expressed in adenovirus can improve the immunogenicity of the GP3 and GP5 of porcine reproductive and respiratory syndrome virus in swine. Vaccine 28: 75147522.

Carrasco CP, Rigden RC, Vincent IE, Balmelli C, Ceppi M, Bauhofer O, Tâche V, Hjertner B, McNeilly F, van Gennip HG, McCullough KC and summerfield A (2004). Interaction of classical swine fever virus with dendritic cells. The Journal of General Virology 85(Pt 6): 1633-1641.

Cassol E, Cassetta L, Alfano M and Poli G (2010). Macrophage polarization and HIV-1 infection. Journal of Leukocyte Biology 87: 599-608.

Cassol E, Cassetta L, Rizzi C, Alfano M and Poli G (2009). M1 and M2a polarization of human monocyte-derived macrophages inhibits HIV-1 replication by distinct mechanisms. Journal of Immunology 182: 6237-6246.

Chang EY, Guo B, Doyle SE and Cheng G (2007). Cutting edge: involvement of the type I IFN production and signaling pathway in lipopolysaccharide-induced IL-10 production. Journal of Immunology 178: 6705-6709.

Chang HW, Pang VF, Chen LJ, Chia MY, Tsai YC and Jeng CR (2006). Bacterial lipopolysaccharide induces porcine circovirus type 2 replication in swine alveolar macrophages. Veterinary Microbiology 115: 311-319.

Chaung HC, Chen CW, Hsieh BL and Chung WB (2010). TollLike receptor expressions in porcine alveolar macrophages and dendritic cells in responding to poly IC stimulation and porcine reproductive and respiratory syndrome virus (PRRSV) infection. Comparative Immunology, Microbiology and Infectious Diseases 33: 197-213.
Chen J and Subbarao K (2007). The Immunobiology of SARS. Annual Review in Immunology 25: 443-472.

Chen Z, Lawson S, Sun Z, Zhou X, Guan X, Christopher-Hennings J, Nelson EA and Fang Y (2010a). Identification of two auto-cleavage products of nonstructural protein 1 (Nsp1) in porcine reproductive and respiratory syndrome virus infected cells: nsp1 function as interferon antagonist. Virology 398: 87-97.

Chen Z, Zhou X, Lunney JK, Lawson S, Sun Z, Brown E, Christopher-Hennings J, Knudsen D, Nelson E and Fang Y (2010b). Immunodominant epitopes in nsp2 of porcine reproductive and respiratory syndrome virus are dispensable for replication, but play an important role in modulation of the host immune response. The Journal of General Virology 91: 1047-1057.

Chitko-McKown CG and Blecha F (1992). Pulmonary intravascular macrophages: a review of immune properties and functions. Annals of Veterinary Research 23: 201-214.

Coffman RL, Sher A and Seder RA (2010). Vaccine adjuvants: putting innate immunity to work. Immunity $\mathbf{3 3}$ : 492-503.

Daffis S, Samuel MA, Keller BC, Gale Jr M and Diamond MS (2007). Cell-specific IRF-3 responses protect against West Nile virus infection by interferon-dependent and-independent mechanisms. PLoS Pathogens 3: e106.

Daher KA, Selsted ME and Lehrer RI (1986). Direct inactivation of viruses by human granulocyte defensins. Journal of Virology 60: 1068-1074.

Darwich L, Díaz I and Mateu E (2010). Certainties, doubts and hypotheses in porcine reproductive and respiratory syndrome virus immunobiology. Virus Research 154: 123-132.

de Los Santos T, de Avila Botton S, Weiblen R and Grubman MJ (2006). The leader proteinase of foot-and-mouth disease virus inhibits the induction of beta interferon mRNA and locks the host innate immune response. Journal of Virology 80: 1906-1914.

de Los Santos T, Diaz-San Segundo F and Grubman MJ (2007). Degradation of Nuclear Factor Kappa B during Foot-andMouth Disease Virus Infection. Journal of Virology 81: 12803-12815.

de los Santos T, Segundo FD, Zhu J, Koster M, Dias CC and Grubman MJ (2009). A conserved domain in the leader proteinase of foot-and-mouth disease virus is required for proper subcellular localization and function. Journal of Virology 83: 1800-1810.

de Oliveira VL, Almeida SC, Soares HR, Crespo A, MarshallClarke S and Parkhouse RM (2011). A novel TLR3 inhibitor encoded by African swine fever virus (ASFV). Archives of Virology 156: 597-609.

Devaraj SG, Wang N, Chen Z, Chen Z, Tseng M, Barretto N, Lin R, Peters CJ, Tseng CT, Baker SC and Li K (2007). Regulation of IRF-3-dependent innate immunity by the papain-like protease domain of the severe acute respiratory syndrome coronavirus. Journal of Biological Chemistry 282: 32208-32221.

Deutsch M and Hadziyannis SJ (2008). Old and emerging therapies in chronic hepatitis C: an update. Journal of Viral Hepatitis 15: 2-11.

Díaz I, Darwich L, Pappaterra G, Pujols J and Mateu E (2006). Different European-type vaccines against porcine reproductive and respiratory syndrome virus have different immunological properties and confer different protection to pigs. Virology 351: 249-259.

Diaz-San Segundo F, Moraes MP, de Los Santos T, Dias CC and Grubman MJ (2010). Interferon-induced protection against foot-and-mouth disease virus infection correlates with enhanced tissue-specific innate immune cell infiltration and 
interferon-stimulated gene expression. Journal of Virology 84: 2063-2077.

Díaz-San Segundo F, Rodríguez-Calvo T, de Avila A and Sevilla N (2009). Immunosuppression during acute infection with foot-and-mouth disease virus in swine is mediated by IL-10. PLoS One 4: e5659.

Ehrhardt C, Seyer R, Hrincius ER, Eierhoff T, Wolff $\mathrm{T}$ and Ludwig S (2010). Interplay between influenza A virus and the innate immune signaling. Microbes and Infection 12: 81-87.

Fang Y and Snijder EJ (2010). The PRRSV replicase: exploring the multifunctionality of an intriguing set of nonstructural proteins. Virus Research 154: 61-76.

Fantuzzi L, Belardelli F and Gessani S (2003). Monocyte/ macrophage-derived CC chemokines and their modulation by HIV-1 and cytokines: a complex network of interactions influencing viral replication and AIDS pathogenesis. Journal of Leukocyte Biology 74: 719-725.

Feng Z, Dubyak GR, Lederman MM and Weinberg A (2006). Cutting edge: human beta defensin 3-a novel antagonist of the HIV-1 coreceptor CXCR4. Journal of Immunology 177: 782-786.

Forsbach A, Nemorin JG, Montino C, Müller C, Samulowitz U, Vicari AP, Jurk M, Mutwiri GK, Krieg AM, Lipford GB and Vollmer J (2008). Identification of RNA Sequence Motifs Stimulating Sequence-Specific TLR8-Dependent Immune Responses. Journal of Immunology 180: 3729-3738.

Fox BA, Sheppard PO and O'Hara PJ (2009). The role of genomic data in the discovery, annotation and evolutionary interpretation of the interferon-lambda family. PLoS One 4: e4933.

García-Sastre A and Biron CA (2006). Type 1 interferons and the virus-host relationship: a lesson in détente. Science 312(5775): 879-882.

Gad HH, Dellgren C, Hamming OJ, Vends S, Paludan SR and Hartmann R (2009). Interferon-lambda is functionally an interferon but structurally related to the interleukin-10 family. Journal of Biological Chemistry 284: 20869-20875.

Gay NJ and Gangloff M (2007). Structure and function of Toll receptors and their ligands. Annual Review of Biochemistry 76: 141-165.

Ge H, Wang YF, Xu J, Gu Q, Liu HB, Xiao PG, Zhou J, Liu Y, Yang $Z$ and Su H (2010). Anti-influenza agents from traditional Chinese medicine. Natural Product Report 27: 1758-1780.

Genini S, Delputte PL, Malinverni R, Cecere M, Stella A, Nauwynck HJ and Giuffra E (2008). Genome-wide transcriptional response of primary alveolar macrophages following infection with porcine reproductive and respiratory syndrome virus. Journal of General Virology 89: 25502564.

Gil S, Sepúlveda N, Albina E, Leitão A and Martins C (2008). The low-virulent African swine fever virus (ASFV/NH/P68) induces enhanced expression and production of relevant regulatory cytokines (IFNalpha, TNFalpha and IL12p40) on porcine macrophages in comparison to the highly virulent ASFV/L60. Archives of Virology 153: 1845-1854.

Haagmans BL and Osterhaus AD (2006). Coronaviruses and their therapy. Antiviral Research 71: 397-403.

Haller O and Weber F (2007). Pathogenic viruses: smart manipulators of the interferon system. Current Topics in Microbiology and Immunology 316: 315-334.

Hammad H and Lambrecht BN (2008). Dendritic cells and epithelial cells: linking innate and adaptive immunity in asthma. Nature Reviews Immunology 8: 193-204.

Hartshorn KL (2010). Role of surfactant protein A and D (SP-A and SP-D) in human antiviral host defense. Frontiers in Bioscience (Scholar Edition). 2: 527-546.
Haselmayer P, Tenzer S, Kwon BS, Jung G, Schild H and Radsak MP (2006). Herpes virus entry mediator synergizes with Toll-like receptor mediated neutrophil inflammatory responses. Immunology 119: 404-411.

Hashimoto Y, Moki T, Takizawa T, Shiratsuchi A and Nakanishi Y (2007). Evidence for phagocytosis of influenza virusinfected, apoptotic cells by neutrophils and macrophages in mice. Journal of Immunology 178: 2448-2457.

He D, Overend C, Ambrogio J, Maganti RJ, Grubman MJ and Garmendia AE (2011). Marked differences between MARC145 cells and swine alveolar macrophages in IFN $\beta$-induced activation of antiviral state against PRRSV. Veterinary Immunology and Immunopathology 139: 57-60.

Herbein G and Varin A (2010). The macrophage in HIV-1 infection: from activation to deactivation? Retrovirology 7: 33.

Herber DL, Cao W, Nefedova Y, Novitskiy SV, Nagaraj S, Tyurin VA, Corzo A, Cho HI, Celis E, Lennox B, Knight SC, Padhya T, McCaffrey TV, McCaffrey JC, Antonia S, Fishman M, Ferris RL, Kagan VE and Gabrilovich DI (2010). Lipid accumulation and dendritic cell dysfunction in cancer. Nature Medicine 16: 880-886.

Hoebe K, Janssen E and Beutler B (2004). The interface between innate and adaptive immunity. Nature Immunology 5: 971974.

Huang YW and Meng XJ (2010). Novel strategies and approaches to develop the next generation of vaccines against porcine reproductive and respiratory syndrome virus (PRRSV). Virus Research 154: 141-149.

Ieong MH, Reardon CC, Levitz SM and Kornfeld H (2000). Human immunodeficiency virus type 1 infection of alveolar macrophages impairs their innate fungicidal activity. American Journal of Respiratory and Critical Care Medicine 162 966-970.

Iannello A, Debbeche O, Martin E, Attalah LH, Samarani S and Ahmad A (2006). Viral strategies for evading antiviral cellular immune responses of the host. Journal of Leukocyte Biology 79: 16-35.

Im SS, Yousef L, Blaschitz C, Liu JZ, Edwards RA, Young SG, Raffatellu M and Osborne TF (2011). Linking lipid metabolism to the innate immune response in macrophages through sterol regulatory element binding protein-1a. Cell Metabolism 13: 540-549.

Iwasaki A (2007). Mucosal dendritic cells. Annual Review of Immunology 25: 381-418.

Jung K, Gurnani A, Renukaradhya GJ and Saif LJ (2010). Nitric oxide is elicited and inhibits viral replication in pigs infected with porcine respiratory coronavirus but not porcine reproductive and respiratory syndrome virus. Veterinary Immunology and Immunopathology 136: 335-339.

Jung K, Renukaradhya GJ, Alekseev KP, Fang Y, Tang Y and Saif LJ (2009). Porcine reproductive and respiratory syndrome virus modifies innate immunity and alters disease outcome in pigs subsequently infected with porcine respiratory coronavirus: implications for respiratory viral co-infections. Journal of General Virology 90: 2713-2723.

Kabelitz D and Medzhitov R (2007). Innate immunity-cross-talk with adaptive immunity through pattern recognition receptors and cytokines. Current Opinion in Immunology 19: $1-3$.

Kalie E, Jaitin DA, Podoplelova Y, Piehler J and Schreiber G (2008). The stability of the ternary interferon-receptor complex rather than the affinity to the individual subunits dictates differential biological activities. Journal of Biological Chemistry 283: 32925-32936.

Karlas A, Machuy N, Shin Y, Pleissner KP, Artarini A, Heuer D, Becker D, Khalil H, Ogilvie LA, Hess S, Mäurer AP, Müller E, Wolff T, Rudel T and Meyer TF (2010). Genome-wide RNAi 
screen identifies human host factors crucial for influenza virus replication. Nature 463: 818-822.

Kato A, Kiyotani K, Kubota T, Yoshida T, Tashiro M and Nagai Y (2007). Importance of the anti-interferon capacity of Sendai virus C protein for pathogenicity in mice. Journal of Virology 81: 3264-3271.

Katze MG, Fornek JL, Palermo RE, Walters KA and Korth MJ (2008). Innate immune modulation by RNA viruses: emerging insights from functional genomics. Nature Reviews Immunology 8: 644-654.

Keirstead ND, Lee C, Yoo D, Brooks AS and Hayes MA (2008). Porcine plasma ficolin binds and reduces infectivity of porcine reproductive and respiratory syndrome virus (PRRSV) in vitro. Antiviral Research 77: $28-38$.

Kim O, Sun Y, Lai FW, Song C and Yoo D (2010). Modulation of type I interferon induction by porcine reproductive and respiratory syndrome virus and degradation of CREBbinding protein by non-structural protein 1 in MARC-145 and HeLa cells. Virology 402: 315-326.

Kimman TG, Cornelissen LA, Moormann RJ, Rebel JM and Stockhofe-Zurwieden N (2009). Challenges for porcine reproductive and respiratory syndrome virus (PRRSV) vaccinology. Vaccine 27: 3704-3718.

Klinge KL, Vaughn EM, Roof MB, Bautista EM and Murtaugh MP (2009). Age-dependent resistance to porcine reproductive and respiratory syndrome virus replication in swine. Virology Journal 6: 177.

Klotman ME and Chang TL (2006). Defensins in innate antiviral immunity. Nature Reviews Immunology 6: 447-456.

Kojima-Shibata C, Shinkai H, Morozumi T, Jozaki K, Toki D, Matsumoto T, Kadowaki H, Suzuki E and Uenishi H (2009). Differences in distribution of single nucleotide polymorphisms among intracellular pattern recognition receptors in pigs. Immunogenetics $\mathbf{6 1}$ : 153-160.

König R, Stertz S, Zhou Y, Inoue A, Hoffmann HH, Bhattacharyya S, Alamares JG, Tscherne DM, Ortigoza MB, Liang Y, Gao Q, Andrews SE, Bandyopadhyay S, De Jesus P, Tu BP, Pache L, Shih C, Orth A, Bonamy G, Miraglia L, Ideker T, García-Sastre A, Young JA, Palese P, Shaw ML and Chanda SK (2010). Human host factors required for influenza virus replication. Nature 463: 813-817.

Kotenko SV, Gallagher G, Baurin VV, Lewis-Antes A, Shen M, Shah NK, Langer JA, Sheikh F, Dickensheets $\mathrm{H}$ and Donnelly RP (2003). IFN-lambdas mediate antiviral protection through a distinct class II cytokine receptor complex. Nature Immunology 4: 69-77.

Koyama S, Ishii KJ, Kumar H, Tanimoto T, Coban C, Uematsu S, Kawai T and Akira S (2007). Differential role of TLR- and RLR-signaling in the immune responses to influenza A virus infection and vaccination. Journal of Immunology 179 $4711-4720$.

Kumagai Y, Takeuchi O, Kato H, Kumar H, Matsui K, Morii E, Aozasa K, Kawai T and Akira S (2007). Alveolar macrophages are the primary interferon-alpha producer in pulmonary infection with RNA viruses. Immunity $\mathbf{2 7}$ 240-252.

Lawson S, Lunney J, Zuckermann F, Osorio F, Nelson E, Welbon $\mathrm{C}$, Clement $\mathrm{T}$, Fang $\mathrm{Y}$, Wong $\mathrm{S}$, Kulas $\mathrm{K}$ and Christopher-Hennings J (2010). Development of an 8-plex luminex assay to detect swine cytokines for vaccine development: assessment of immunity after porcine reproductive and respiratory syndrome virus (PRRSV) vaccination. Vaccine 28: 5356-5364.

Lee HK and Iwasaki A (2008). Autophagy and antiviral immunity. Current Opinion in Immunology 20: 23-29.
Lee MS and Kim YJ (2007). Signaling pathways downstream of pattern-recognition receptors and their crosstalk. Annual Review of Biochemistry 76: 447-480.

Lee SM, Schommer SK and Kleiboeker SB (2004). Porcine reproductive and respiratory syndrome virus field isolates differ in in vitro interferon phenotypes. Veterinary Immunology and Immunopathology 102: 217-231.

Lehrer RI (2007). Multispecific myeloid defensins. Current Opinion in Hematology 14: 16-21.

Leung PC (2007). The efficacy of Chinese medicine for SARS: a review of Chinese publications after the crisis. American Journal of Chinese Medicine 35: 575-581.

Li G, Jiang P, Li Y, Wang X, Huang J, Bai J, Cao J, Wu B, Chen N and Zeshan B (2009a). Inhibition of porcine reproductive and respiratory syndrome virus replication by adenovirus-mediated RNA interference both in porcine alveolar macrophages and swine. Antiviral Research 82: $157-165$.

Li H, Zheng Z, Zhou P, Zhang B, Shi Z, Hu Q and Wang H (2010). The cysteine protease domain of porcine reproductive and respiratory syndrome virus non-structural protein 2 antagonizes interferon regulatory factor 3 activation. Journal of General Virology 91: 2947-2958.

Li J, Jiang P, Li Y, Wang X, Cao J, Wang X and Zeshan B (2009b). HSP70 fused with GP3 and GP5 of porcine reproductive and respiratory syndrome virus enhanced the immune responses and protective efficacy against virulent PRRSV challenge in pigs. Vaccine 27: 825-832.

Liu CH, Chaung HC, Chang HL, Peng YT and Chung WB (2009). Expression of Toll-like receptor mRNA and cytokines in pigs infected with porcine reproductive and respiratory syndrome virus. Veterinary Microbiology 136: 266-276.

Longworth KE (1997). The comparative biology of pulmonary intravascular macrophages. Frontiers in Bioscience 2: d232-241

Loo YM and Gale Jr M (2007). Viral regulation and evasion of the host response. Current Topics in Microbiology and Immunology 316: 295-313.

Loving CL, Brockmeier SL and Sacco RE (2007). Differential type I interferon activation and susceptibility of dendritic cell populations to porcine arterivirus. Immunology 120: 217-229.

Loving CL, Brockmeier SL, Vincent AL, Lager KM and Sacco RE (2008). Differences in clinical disease and immune response of pigs challenged with a high-dose versus lowdose inoculum of porcine reproductive and respiratory syndrome virus. Viral Immunology 21: 315-325.

Lu L, Ho Y and Kwang J (2006). Suppression of porcine arterivirus replication by baculovirus-delivered shRNA targeting nucleoprotein. Biochemical and Biophysical Research Communications 340: 1178-1183.

Ludwig IS, Geijtenbeek TB and van Kooyk Y (2006). Two way communication between neutrophils and dendritic cells. Current Opinion in Pharmacology 6: 408-413.

Lunney JK, Fritz ER, Reecy JM, Kuhar D, Prucnal E, Molina R, Christopher-Hennings J, Zimmerman $\mathrm{J}$ and Rowland RR (2010). Interleukin-8, interleukin-1beta, and interferongamma levels are linked to PRRS virus clearance. Viral Immunology 23: 127-134.

Luo R, Fang L, Jiang Y, Jin H, Wang Y, Wang D, Chen H and Xiao $S$ (2011). Activation of NF- $\kappa B$ by nucleocapsid protein of the porcine reproductive and respiratory syndrome virus. Virus Genes 42: 76-81.

Luo R, Xiao S, Jiang Y, Jin H, Wang D, Liu M, Chen H and Fang L (2008). Porcine reproductive and respiratory syndrome virus (PRRSV) suppresses interferon-beta production by interfering with the RIG-I signaling pathway. Molecular Immunology 45: 2839-2846. 
Martinelli E, Cicala C, Van Ryk D, Goode DJ, Macleod K, Arthos J and Fauci AS (2007). HIV-1 gp120 inhibits TLR9-mediated activation and IFN-\{alpha\} secretion in plasmacytoid dendritic cells. Proceedings of the National Academy of Sciences of the United States of America 104: 3396-3401.

Martinez FO, Helming L and Gordon S (2009). Alternative activation of macrophages: an immunologic functional perspective. Annual Review of Immunology 27: 451-483.

Miller LC, Laegreid WW, Bono JL, Chitko-McKown CG and Fox JM (2004). Interferon type I response in porcine reproductive and respiratory syndrome virus-infected MARC-145 cells. Archives of Virology 149: 2453-2463.

Miller LC, Lager KM and Kehrli Jr ME (2009). Role of Toll-like receptors in activation of porcine alveolar macrophages by porcine reproductive and respiratory syndrome virus. Clinical and Vaccine Immunology 16: 360-365.

Monsalvo AC, Batalle JP, Lopez MF, Krause JC, Klemenc J, Hernandez JZ, Maskin B, Bugna J, Rubinstein C, Aguilar L, Dalurzo L, Libster R, Savy V, Baumeister E, Aguilar L, Cabral G, Font J, Solari L, Weller KP, Johnson J, Echavarria M, Edwards KM, Chappell JD, Crowe Jr JE, Williams JV, Melendi GA and Polack FP (2011). Severe pandemic 2009 H1N1 influenza disease due to pathogenic immune complexes. Nature Medicine 17: 195-199.

Munir S, Le Nouen C, Luongo C, Buchholz UJ, Collins PL and Bukreyev A (2008). Nonstructural proteins 1 and 2 of respiratory syncytial virus suppress maturation of human dendritic cells. Journal of Virology 82: 8780-8796.

Murtaugh MP, Stadejek T, Abrahante JE, Lam TT and Leung FC (2010). The ever-expanding diversity of porcine reproductive and respiratory syndrome virus. Virus Research 154: $18-30$.

Music N and Gagnon CA (2010). The role of porcine reproductive and respiratory syndrome (PRRS) virus structural and non-structural proteins in virus pathogenesis. Animal Health Research Reviews 11: 135-163.

Naito M (2008). Macrophage differentiation and function in health and disease. Pathology International 58: 143-155.

Odegaard JI and Chawla A (2011). Alternative Macrophage Activation and Metabolism. Annual Review in Patbology 6: 275-297.

Onoguchi K, Yoneyama M, Takemura A, Akira S, Taniguchi T, Namiki H and Fujita T (2007). Viral infections activate types I and III interferon genes through a common mechanism. Journal of Biological Chemistry 282: 75767581.

Opitz B, Hippenstiel S, Eitel J and Suttorp N (2007). Extra- and intracellular innate immune recognition in endothelial cells. Thrombosis and Haemostasis 98: 319-326.

Pancer Z and Cooper MD (2006). The evolution of adaptive immunity. Annual Review in Immunology 24: 497-518.

Patel D, Nan Y, Shen M, Ritthipichai K, Zhu X and Zhang YJ (2010). Porcine reproductive and respiratory syndrome virus inhibits type I interferon signaling by blocking STAT1/ STAT2 nuclear translocation. Journal of Virology 84: 1104511055 .

Patton JB, Rowland RR, Yoo D and Chang KO (2009). Modulation of CD163 receptor expression and replication of porcine reproductive and respiratory syndrome virus in porcine macrophages. Virus Research 140: 161-171.

Pestka S (2007). The interferons: 50 years after their discovery, there is much more to learn. Journal of Biological Chemistry 282: 20047-20051.

Pichlmair A and Reis e Sousa C (2007). Innate recognition of viruses. Immunity 27: 370-383.

Qiao S, Feng L, Bao D, Guo J, Wan B, Xiao Z, Yang S and Zhang $G$ (2011). Porcine reproductive and respiratory syndrome virus and bacterial endotoxin act in synergy to amplify the inflammatory response of infected macrophages. Veterinary Microbiology 149: 213-220.

Randolph GJ, Jakubzick C and Qu C (2008). Antigen presentation by monocytes and monocyte-derived cells. Current Opinion in Immunology 20: 52-60.

Rowland RR (2010). The interaction between PRRSV and the late gestation pig fetus. Virus Research 154: 114-122.

Rowland RR, Robinson B, Stefanick J, Kim TS, Guanghua L, Lawson SR and Benfield DA (2001). Inhibition of porcine reproductive and respiratory syndrome virus by interferongamma and recovery of virus replication with 2-aminopurine. Archives of Virology 146: 539-555.

Saenz SA, Noti M and Artis D (2010). Innate immune cell populations function as initiators and effectors in Th2 cytokine responses. Trends in Immunology 31: 407-413.

Salvatore M, Garcia-Sastre A, Ruchala P, Lehrer RI, Chang T and Klotman ME (2007). alpha-Defensin inhibits influenza virus replication by cell-mediated mechanism(s). Journal of Infectious Diseases 196: 835-843.

Sanders CM, Cruse JM and Lewis RE (2008). Toll-like receptors, cytokines and HIV-1. Experimental and Molecular Pathology 84: 31-36.

Sang Y and Blecha F (2008). Antimicrobial peptides and bacteriocins: alternatives to traditional antibiotics. Animal Health Research Reviews 9: 227-235.

Sang Y and Blecha F (2009). Porcine host defense peptides: expanding repertoire and functions. Developmental and Comparative Immunology 33: 334-343.

Sang Y, Ross CR, Rowland RR and Blecha F (2008b). Toll-like receptor 3 activation decreases porcine arterivirus infection. Viral Immunology 21: 303-313.

Sang Y, Rowland RR and Blecha F (2010b). Molecular characterization and antiviral analyses of porcine type III interferons. Journal of Interferon and Cytokine Research 30: 801-807.

Sang Y, Rowland RR, Hesse RA and Blecha F (2010a). Differential expression and activity of the porcine type I interferon family. Physiological Genomics. 42: 248-258.

Sang Y, Ruchala P, Lehrer RI, Ross CR, Rowland RR and Blecha F (2009). Antimicrobial host defense peptides in an arteriviral infection: differential peptide expression and virus inactivation. Viral Immunology 22: 235-242.

Sang Y, Yang J, Ross CR, Rowland RR and Blecha F (2008a). Molecular identification and functional expression of porcine Toll-like receptor (TLR) 3 and TLR7. Veterinary Immunology and Immunopathology 125: 162-167.

Sawa S, Cherrier M, Lochner M, Satoh-Takayama N, Fehling HJ, Langa F, Di Santo JP and Eberl G (2010). Lineage relationship analysis of RORgammat+innate lymphoid cells. Science 330: 665-669.

Schlender J, Hornung V, Finke S, Günthner-Biller M, Marozin S, Brzózka K, Moghim S, Endres S, Hartmann G and Conzelmann KK (2005). Inhibition of toll-like receptor 7and 9-mediated alpha/beta interferon production in human plasmacytoid dendritic cells by respiratory syncytial virus and measles virus. Journal of Virology 79: 5507-5515.

Schmid D, Dengjel J, Schoor O, Stevanovic S and Münz C (2006). Autophagy in innate and adaptive immunity against intracellular pathogens. Journal of Molecular Medicine 84: 194-202.

Sen GC and Sarkar SN (2007). The interferon-stimulated genes: targets of direct signaling by interferons, double-stranded RNA, and viruses. Current Topics in Microbiology and Immunology 316: 233-250.

Sheahan T, Morrison TE, Funkhouser W, Uematsu S, Akira S, Baric RS and Heise MT (2008). MyD88 is required for protection from lethal infection with a mouse-adapted SARS-CoV. PLoS Pathogens 4: e1000240. 
Sheppard P, Kindsvogel W, Xu W, Henderson K, Schlutsmeyer S, Whitmore TE, Kuestner R, Garrigues U, Birks C, Roraback J, Ostrander C, Dong D, Shin J, Presnell S, Fox B, Haldeman B, Cooper E, Taft D, Gilbert T, Grant FJ, Tackett M, Krivan W, McKnight G, Clegg C, Foster D and Klucher KM (2003). IL-28, IL-29 and their class II cytokine receptor IL-28R. Nature Immunology 4:63-68.

Shi X, Wang L, Zhi Y, Xing G, Zhao D, Deng R and Zhang G (2010). Porcine reproductive and respiratory syndrome virus (PRRSV) could be sensed by professional beta interferon-producing system and had mechanisms to inhibit this action in MARC-145 cells. Virus Research 153: 151-156.

Shinkai H, Muneta Y, Suzuki K, Eguchi-Ogawa T, Awata T and Uenishi H (2006a). Porcine Toll-like receptor 1, 6, and 10 genes: complete sequencing of genomic region and expression analysis. Molecular Immunology 43: 1474-1480.

Shinkai H, Tanaka M, Morozumi T, Eguchi-Ogawa T, Okumura N, Muneta Y, Awata T and Uenishi H (2006b). Biased distribution of single nucleotide polymorphisms (SNPs) in porcine Toll-like receptor 1 (TLR1), TLR2, TLR4, TLR5, and TLR6 genes. Immunogenetics 58: 324-330.

Shirey KA, Pletneva LM, Puche AC, Keegan AD, Prince GA, Blanco JC and Vogel SN (2010). Control of RSV-induced lung injury by alternatively activated macrophages is IL- $4 \mathrm{R}$ alpha-, TLR4-, and IFN-beta-dependent. Mucosal Immunology 3: 291-300.

Silva-Campa E, Cordoba L, Fraile L, Flores-Mendoza L, Montoya M and Hernández J (2010). European genotype of porcine reproductive and respiratory syndrome (PRRSV) infects monocyte-derived dendritic cells but does not induce Treg cells. Virology 396: 264-271.

Skalsky RL and Cullen BR (2010). Viruses, microRNAs, and host interactions. Annual Review of Microbiology 64: 123-141.

Song C, Krell P and Yoo D (2010). Nonstructural protein $1 \alpha$ subunit-based inhibition of NF- $\kappa \mathrm{B}$ activation and suppression of interferon- $\beta$ production by porcine reproductive and respiratory syndrome virus. Virology 407: 268-280.

Spiegel S and Milstien S (2011). The outs and the ins of sphingosine-1-phosphate in immunity. Nature Reviews. Immunology 11: 403-415.

Stout RD, Jiang C, Matta B, Tietzel I, Watkins SK and Suttles J (2005). Macrophages sequentially change their functional phenotype in response to changes in microenvironmental influences. Journal of Immunology 175: 342-349.

Stout RD, Watkins SK and Suttles J (2009). Functional plasticity of macrophages: in situ reprogramming of tumor-associated macrophages. Journal of Leukocyte Biology 86: 1105-1109.

Subramaniam S, Sur JH, Kwon B, Pattnaik AK and Osorio FA (2011). A virulent strain of porcine reproductive and respiratory syndrome virus does not up-regulate interleukin-10 levels in vitro or in vivo. Virus Research 155: 415422.

Sulkowski MS and Benhamou Y (2007). Therapeutic issues in HIV/HCV-coinfected patients. Journal of Viral Hepatitis 14: 371-386.

Sun Z, Chen Z, Lawson SR and Fang Y (2010). The cysteine protease domain of porcine reproductive and respiratory syndrome virus nonstructural protein 2 possesses deubiquitinating and interferon antagonism functions. Journal of Virology 84: 7832-7846.

Takaoka A, Wang Z, Choi MK, Yanai H, Negishi H, Ban T, Lu Y, Miyagishi M, Kodama T, Honda K, Ohba Y and Taniguchi T (2007). DAI (DLM-1/ZBP1) is a cytosolic DNA sensor and an activator of innate immune response. Nature $\mathbf{4 4 8}(7152)$ : 501-505.

Takaoka A and Yanai H (2006). Interferon signalling network in innate defence. Cellular Microbiology 8: 907-922.
Takeuchi O and Akira S (2007). Recognition of viruses by innate immunity. Immunological Reviews 220: 214-224.

Taylor PR, Martinez-Pomares L, Stacey M, Lin HH, Brown GD and Gordon S (2005). Macrophage receptors and immune recognition. Annual Review of Immunology 23: 901-944.

Teijaro JR, Walsh KB, Cahalan S, Fremgen DM, Roberts E, Scott F, Martinborough E, Peach R, Oldstone MB and Rosen $\mathrm{H}$ (2011). Endothelial cells are central orchestrators of cytokine amplification during influenza virus infection. Cell 146: 980-991.

Thanawongnuwech R, Halbur PG and Thacker EL (2000). The role of pulmonary intravascular macrophages in porcine reproductive and respiratory syndrome virus infection. Animal Health Research Reviews 1: 95-102.

Thanawongnuwech R and Suradhat S (2010). Taming PRRSV: revisiting the control strategies and vaccine design. Virus Research 154: 133-140.

Thibault S, Fromentin R, Tardif MR and Tremblay MJ (2009). TLR2 and TLR4 triggering exerts contrasting effects with regard to HIV-1 infection of human dendritic cells and subsequent virus transfer to CD $4+\mathrm{T}$ cells. Retrovirology $\mathbf{6}$ : 42.

Umbach JL and Cullen BR (2009). The role of RNAi and microRNAs in animal virus replication and antiviral immunity. Genes and Development 23: 1151-1164.

Uzé G, Schreiber G, Piehler J and Pellegrini S (2007). The receptor of the type I interferon family. Current Topics in Microbiology and Immunology 316: 71-95.

Van Gorp H, Van Breedam W, Delputte PL and Nauwynck HJ (2008). Sialoadhesin and CD163 join forces during entry of the porcine reproductive and respiratory syndrome virus. Journal of General Virology 89: 2943-2953.

Veldhoen $M$ and Withers DR (2010). Immunology. Innate lymphoid cell relations. Science 330: 594-595.

Vincent IE, Balmelli C, Meehan B, Allan G, Summerfield A and McCullough KC (2007). Silencing of natural interferon producing cell activation by porcine circovirus type 2 DNA. Immunology 120: 47-56.

Vivier E, Tomasello E, Baratin M, Walzer T and Ugolini S (2008). Functions of natural killer cells. Nature Immunology 9: 503510

Wang D, Fang L, Li T, Luo R, Xie L, Jiang Y, Chen H and Xiao S (2008). Molecular cloning and functional characterization of porcine IFN-beta promoter stimulator 1 (IPS-1). Veterinary Immunology and Immunopathology 125: 344-353.

Wang H, Brown J, Garcia CA, Tang Y, Benakanakere MR, Greenway T, Alard P, Kinane DF and Martin M (2011). The role of glycogen synthase kinase 3 in regulating IFN-betamediated IL-10 production. Journal of Immunology 186: 675-684.

Wang X, Li J, Jiang P, Li Y, Zeshan B, Cao J and Wang X (2009). GM-CSF fused with GP3 and GP5 of porcine reproductive and respiratory syndrome virus increased the immune responses and protective efficacy against virulent PRRSV challenge. Virus Research 143: 24-32.

Welch SK and Calvert JG (2010). A brief review of CD163 and its role in PRRSV infection. Virus Research 154: 98-103.

Wen H, Schaller MA, Dou Y, Hogaboam CM and Kunkel SL (2008). Dendritic cells at the interface of innate and acquired immunity: the role for epigenetic changes. Journal of Leukocyte Biology 83: 439-446.

West AP, Koblansky AA and Ghosh S (2006). Recognition and signaling by toll-like receptors. Annual Review of Cell and Developmental Biology 22: 409-437.

White MR, Tecle T, Crouch EC and Hartshorn KL (2007). Impact of neutrophils on antiviral activity of human bronchoalveolar lavage fluid. American Journal of Physiology: Lung Cellular and Molecular Physiology 293: L1293-1299. 
Wikström FH, Fossum C, Fuxler L, Kruse R and Lövgren T (2011). Cytokine induction by immunostimulatory DNA in porcine PBMC is impaired by a hairpin forming sequence motif from the genome of Porcine Circovirus type 2 (PCV2). Veterinary Immunology and Immunopatbology 139: $156-166$

Xiao S, Jia J, Mo D, Wang Q, Qin L, He Z, Zhao X, Huang Y, Li A, Yu J, Niu Y, Liu X and Chen Y (2010b). Understanding PRRSV infection in porcine lung based on genome-wide transcriptome response identified by deep sequencing. PLoS One 5: e11377.

Xiao S, Mo D, Wang Q, Jia J, Qin L, Yu X, Niu Y, Zhao X, Liu X and Chen Y (2010a). Aberrant host immune response induced by highly virulent PRRSV identified by digital gene expression tag profiling. BMC Genomics 11: 544.

Yoo D, Song C, Sun Y, Du Y, Kim O and Liu HC (2010). Modulation of host cell responses and evasion strategies for porcine reproductive and respiratory syndrome virus. Virus Research 154: 48-60.

Zhang F, Hopwood P, Abrams CC, Downing A, Murray F, Talbot R, Archibald A, Lowden S and Dixon LK (2006). Macrophage transcriptional responses following in vitro infection with a highly virulent African swine fever virus isolate. Journal of Virology 80: 1051410521.

Zhang X, Wang C, Schook LB, Hawken RJ and Rutherford MS (2000). An RNA helicase, RHIV -1, induced by porcine reproductive and respiratory syndrome virus (PRRSV) is mapped on porcine chromosome 10q13. Microbial Pathogenesis 28: 267-278.

Zuniga EI, Hahm B and Oldstone MB (2007). Type I interferon during viral infections: multiple triggers for a multifunctional mediator. Current Topics in Microbiology and Immunology 316: 337-357. 